\title{
Synthesis and anti-Trypanosoma cruzi profile of the novel 4-thiazolidinone and 1,3-thiazole derivatives
}

\author{
de Siqueira LRP ${ }^{1}$, de Oliveira Barbosa $\mathrm{M}^{1}$, Oliveira AR ${ }^{1}$, de Moraes Gomes PAT ${ }^{1}$, de Oliveira Filho GB ${ }^{1,2}$, de Oliveira Cardoso MV ${ }^{3}$, Pereira \\ $\mathrm{VRA}^{4}$, da Silva Santos $\mathrm{AC}^{4}$, Júnior PAS ${ }^{5}$, Romanha $\mathrm{AJ}^{5}$ and Leite $\mathrm{ACL}^{1 *}$ \\ ${ }^{1}$ Laboratório de Planejamento em Química Medicinal, Departamento de Ciências Farmacêuticas, Centro de Ciências da Saúde, Universidade Federal de Pernambuco, \\ 50740-520, Recife, PE, Brazil \\ ${ }^{2}$ Coordenação do Curso de Farmácia, Faculdade de Integração do Sertão, 56909-205, Serra Talhada-PE, Brazil \\ ${ }^{3}$ Laboratório de Prospecção de Moléculas Bioativas, Universidade de Pernambuco, 56328-903, Petrolina, PE, Brazil \\ ${ }^{4}$ Centro de Pesquisas Aggeu Magalhães, Fundação Oswaldo Cruz, 50670-420, Recife, \\ PE, Brazil
}

${ }^{5}$ Laboratório de Parasitologia Celular e Molecular, Centro de Pesquisas René Rachou, Fundação Oswaldo Cruz, 30.190-002, MG, Brazil

\begin{abstract}
Chagas disease is a serious public health problem in Brazil and world. Caused by the protozoan Trypanosoma cruzi, it is estimated 6-7 million people infected worldwide. The only drug used to treatment is Benzonidazole, but this drug is only effective in the acute phase of the disease. This paper reports the synthesis and the anti-Trypanosoma cruzi activity of 4-thiazolidinone and 1,3-thiazole derivatives based in thiosemicarbazones previously described as potent trypanocidal agent, planned through the bioisosterism strategy. Therefore, the synthesis of 28 aryl-4-thiazolidinones (2a-r and 3a-j) was achieved, which aryl ring possesses halogens atoms in meta and para positions, and the heterocyclic system had lipophilic substituents. These compounds were thus evaluated as anti-T. cruzi agents against epimastigote, trypomastigote and amastigote forms of T. cruzi. Compounds were also tested its toxicity in L929 fibroblasts. In view to investigate a bioisosteric relationship between 1,3-thiazoles and 4-thiazolidinones, eighteen 1,3- thiazoles derived from trifluoromethyl thiosemicarbazone (4a-r) were also tested in the same model. It was possible to show that between the 46 tested compounds, those that possess a bromine (2a-r) atom showed better activity compared to compounds substituted by a trifluoromethyl group (3a-j) and to 1,3-thiazole derivatives (4a-r), which were inactive. In general, the $\mathbf{2} \mathbf{a}-\mathbf{r}$ series showed low toxic profile in the cell line tested. Besides, compound $2 \mathbf{h}$ was the most active of then all when compared to the standard Benznidazole.
\end{abstract}

\section{Introduction}

Chagas disease or American Trypanosomiasis is a serious disease resulting from parasitic infection by the protozoan Trypanosoma cruzi, and triatomine insects as vectors [1,2]. About 7 million people are infected worldwide and Latin America countries are endemic areas. It is estimated that $30 \%$ of chronically infected people develop cardiac disorders and up to $10 \%$ develop digestive, neurological or mixed changes that may require special treatment [1-3].

Currently, the only drugs used in Chagas disease therapy are Benznidazole (BZD) and nifurtimox, which are effective in the acute phase of the disease, but less effectivity in patients in the chronic phase, presenting only palliative effect $[2,4-7]$. Furthermore, BZD is not considered a suitable drug, since exhibits serious side effects such as hypersensitivity, rash, gastrointestinal disorder etc., leading to a large number of patients interruption the treatment $[2,8]$. Therefore, the search for new drugs and bioactive molecules more selective is pivotal.

Among the chemical structures studied for anti-T. cruzi activity, hydrazones and 4-thiazolidinones are notable because of their extensive biological activity [9-18], especially anti-parasitic activities [10,16-20]. Some papers already published investigated bioactive compounds against Chagas disease, however, a noticeable paper published by 21 , identified twenty aryl thiosemicarbazones as potent anti- $T$. cruzi drug prototypes, with $\mathrm{IC}_{50}$ values below $200 \mathrm{nM}$ for T. cruzi cruzain [21]. Among these compounds previously evaluated, 3'-bromopropiophenone- thiosemicarbazone (1i) and 3-(trifluoromethyl)thiosemicarbazone (3d) were identified as leading compounds (Figure 1).

In this context, it is well noticed that several drugs and drug candidates in clinical development possess halogen atoms in their structures $[7,22]$. In fact, they contribute favorably through a molecular interaction in the stabilization of the protein-ligand complex. In addition, synthesis of fluorine, chlorine, and bromine derivatives are well known in industrial scale and possess desirable stability and cost [23].

In the last few years, our research group had been used the building-block strategy in view to optimize the antiparasitical profile. Recently, the 1,3-thiazole core was obtained from 3'-bromopropiophenone-thiosemicarbazone and trifluoromethylthiosemicarbazone in view to access new lead generation of anti- $T$.

${ }^{*}$ Correspondence to: Ana Cristina Lima Leite, Laboratório de Planejamento em Química Medicinal, Departamento de Ciências Farmacêuticas, Centro de Ciências da Saúde, Universidade Federal de Pernambuco, 50740-520, Recife, PE, Brazil, E-mail: acllb2003@yahoo.com.br

Key words: chagas disease, Anti-T. cruzi agents, thiosemicarbazone, 1,3-thiazoles, 4-thiazolidinones

Received: January 25, 2019; Accepted: February 15, 2019; Published: February 20,2019 
cruzi agents. In fact, most of these compounds exhibited antiparasitic activity similar to BZD [24] (Figure 1).

Bearing in mind the bioisosteric relationship between 1,3-thiazole and 4-thiazolidinone cores and by the promising results obtained by Moraes (2016) and Du (2002), in this work, our group presents two series of 4-thiazolidinones, derived by 3'-bromopropriophenonethiosemicarbazone and 3-(trifluoromethyl)thiosemicarbazone (2a$\mathbf{r}$ and 3a-j, respectively), in view to achieve novel and more selective candidates against T. cruzi. In this approach, 28 compounds were synthesized with variations lipophilic groups inserted at N3 and C5 positions of the 4-thiazolidinone ring. In addition, these compounds were evaluated for their trypanocidal potential in the epimastigote, trypomastigote and amastigote forms of the parasite, and their cytotoxicity was tested in L929 fibroblast cells. Analyzing the activity against the three T. cruzi forms is important in an attempt to clarify the mechanism of action of compounds. In view to make a structureactivity biological profile between 1,3-thiazole and 4-thiazolidinone nucleus, we also evaluated the anti- $T$. cruzi properties of eighteen 1,3-thiazoles derived from (trifluoromethyl)thiosemicarbazone (4a-r).

\section{Results and discussion}

\section{Chemistry}

For the synthesis of the desired compounds, the procedures previously reported by 10,25 were followed. First, the thiosemicarbazones $\mathbf{1 d}$ and $\mathbf{1 e}$ were prepared by reacting commercially available thiosemicarbazide or methyl thiosemicarbazide, with 4-(trifluoromethyl)benzaldehyde (1:1 mol ratio) using ethanol, under reflux, in the presence of catalytic amount of hydrochloric acid, for 3 hours. After the final reaction, water was added for precipitation of the compounds. This reaction led to a satisfactory yield (85\% for compound 1d and $94 \%$ for compound 1e). The thiazolidin-4-ones (3a-j) were prepared by cyclization of compounds 1d or 1e and respective acid/ester, under reflux for 24 hours. The precipitate was filtered in Büchner funnel, washed with cold ethanol, and then dried over $\mathrm{SiO}_{2}$. The yields were satisfactory (>40\%). The synthesis of $\mathbf{4 a - r}$ series is described by [25].

In view to set up the structural planning of the 4-thiazolidinone series $\mathbf{2} \mathbf{a}-\mathbf{r}$ and $\mathbf{3} \mathbf{a}-\mathbf{j}$, the aimed perspectives were based on followed points: a) the choice of the halogen (bromine or fluorine), positions to be inserted (meta or para) in the aryl ring, employing 3-bromophenyl propanone or 4-(trifluoromethyl)benzaldehyde; b) the lipophilic and steric profile of the substituents at C5 position, adopting different esters; c) attachment of a methyl or phenyl group at nitrogen N3 by applying 4-methyl or 4-phenyl-thiosemicarbazide. About the ethyl group present at $R_{2}$ position in the series 2a-r coming from the ketone used (Scheme 1). Therefore, two thiazolidinones series were synthesized: 2a-r and 3a-j. For synthesis of desired compounds (Scheme 1), it was followed procedures previously described by [10].

Regarding 1,3-thiazole series (4a-r), variations were made in the group linked to 4 position of the thiazole ring, through the insertion of aromatic rings with different substitutions in ortho, meta and para positions (Figure 2). The synthesis of series 4a-r followed the procedures described by de Oliveira [26], and is described by 25 . The chemical structures of compounds were determined by nuclear magnetic resonance (NMR, ${ }^{1} \mathrm{H}$, and ${ }^{13} \mathrm{C}$ ), infrared (I.R.) and mass spectra (HRMS), while purity was determined by elemental analysis (EA).

\section{Biological evaluation}

The in vitro anti-T. cruzi activity of compounds for epimastigote, trypomastigote and amastigote T. cruzi forms was evaluated, and
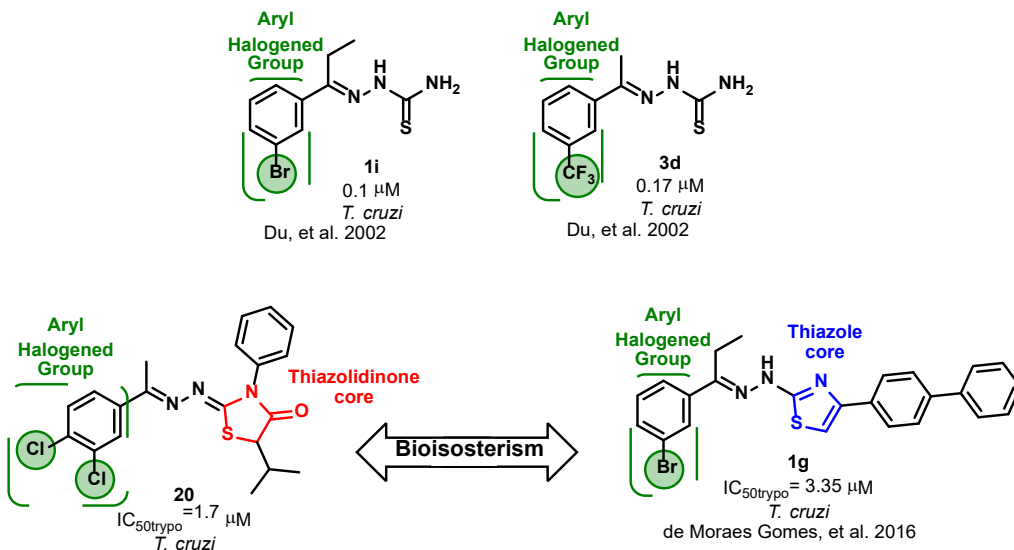

de Oliveira Filho, et al. 2015

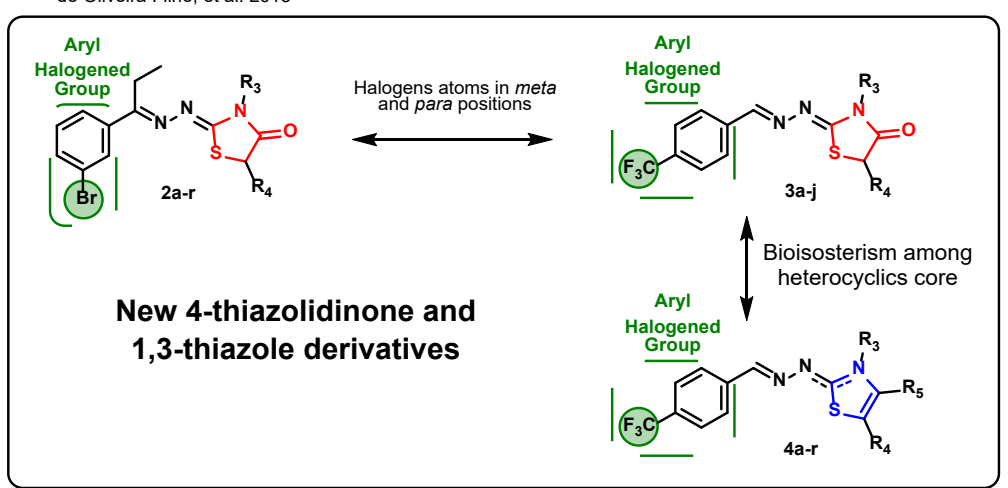

Figure 1. The influence of halogen groups in the anti T. cruzi activity and proposed compounds in this work (2a-r, 3a-j and 4a-r). [10,21,23,24] 


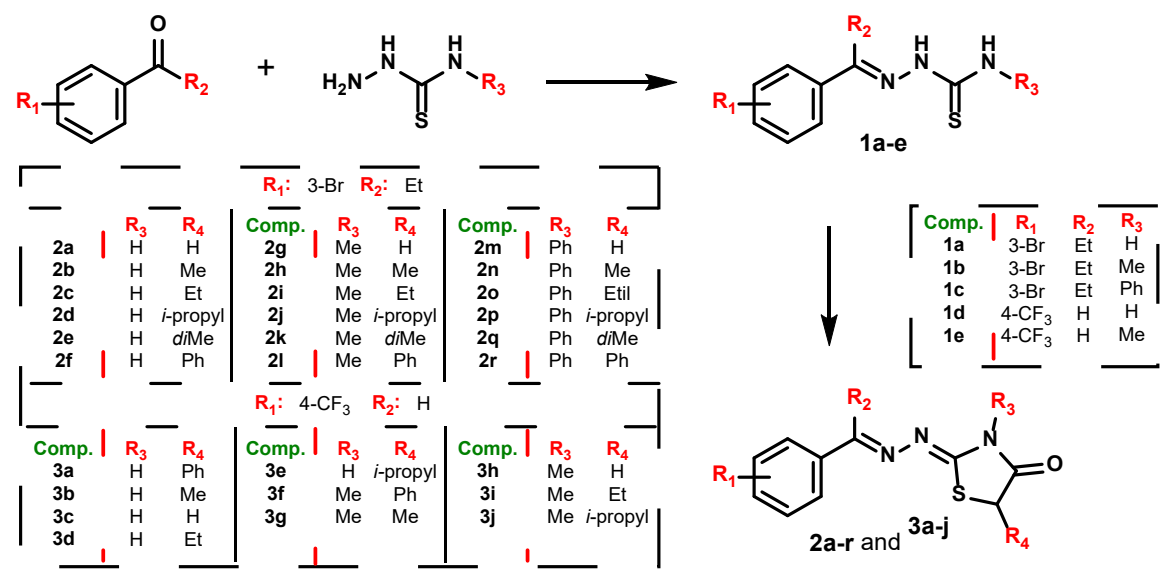

Scheme 1. Synthetic procedures of 4-thiazolidinones derivatives

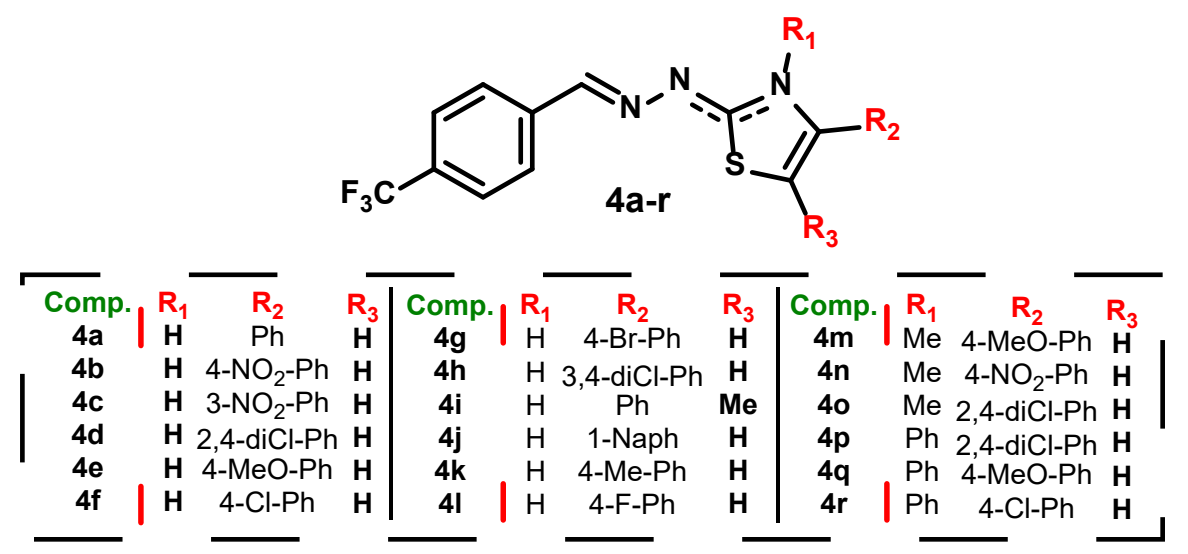

Figure 2. Series 4a-r, variations in the group linked to 4 position of the thiazole ring

their toxicity was evaluated in L929 fibroblasts. Among the tested compounds, the series 2a-r showed the best results when compared with $\mathbf{3 a}-\mathbf{j}$ series. The $\mathbf{2 a - r}$ series possess a bromine atom at the position 3 of the aryl ring system and the $\mathbf{3} \mathbf{a}-\mathbf{j}$ series possess a trifluoromethyl group at position 4 of aryl ring system.

In recent studies [24] a series of 1,3-thiazoles derived from 3-(bromopropiophenone) thiosemicarbazone were synthesized and their results demonstrated similar activity to BZD (T. cruzi trypomastigote form). Furthermore, compounds possessing halogens in their structure (fluorine and bromine), in general, exhibit interesting biological activities and interactions [23] in perspective of these promising outcomes, we decided to explore the anti-T. cruzi potential of bromine (series 2a-r) and trifluoromethyl group (series 3a-j) 4-thiazolidinone derivatives.

Considering the trypanocidal activity of the intermediates 1a-e, and the series $\mathbf{2 a - r}$ and $\mathbf{3 a - j}$, for trypomastigote form, the intermediate thiosemicarbazones $\mathbf{1 b}$ and $\mathbf{1 c}$, with $\mathrm{IC}_{50}=5.0 \mu \mathrm{M}$ and $\mathrm{IC}_{50}=2.3$ $\mu \mathrm{M}$, respectively, presented the best results of all tested compounds. Regarding the series 2 , compounds $2 \mathbf{n}\left(\mathrm{IC}_{50}=3.7 \mu \mathrm{M}\right), \mathbf{2} \mathbf{l}\left(\mathrm{IC}_{50}=7.9\right.$ $\mu \mathrm{M})$, and $2 \mathbf{d}\left(\mathrm{IC}_{50}=8.1 \mu \mathrm{M}\right)$ draw attention, all of them had anti-T. cruzi activity against trypomastigote form similar to BZD, however, no correlation of structural features can be drawn.

For series 3, which possesses the core thiazolidine-4-one, the compound 3d $\left(\mathrm{IC}_{50}=7.8 \mu \mathrm{M}\right)$ was the most active of 3 series. The insertion of an group containing halogen at the para position (series 3a-j), was not beneficial for the activity against the trypomastigote form when compared to series $2 \mathbf{a}-\mathbf{r}$.

Considering the inhibitory activity of amastigote forms for the entire series, only compound $\mathbf{2 h}$ was active, being more potent than BZD, with an $\mathrm{IC}_{50}=2.4 \mu \mathrm{M}$. The notable feature of compound $\mathbf{2 h}$ is, besides $\mathrm{Br}$ atom present at the position 3 of the aryl ring, 4 -thiazolidinone ring, possess a methyl group in N3 position and a methyl group in $\mathrm{C} 5$.

About the substitutions in N3 it was noticed that the insertion of the methyl group was responsible for the increase the activity. Also, between the compounds $\mathbf{2 a}, \mathbf{2 g}$, and $\mathbf{2 m}$, it was possible to verify that the methyl group is pivotal to the reduction of $\mathrm{IC}_{50}$.

The compounds 1a-e, thiosemicarbazones that originated the respective 4-thiazolidinones, can be observed that intermediates $1 \mathbf{a}$ and 1d, which possess $\mathrm{H}$ in $\mathrm{R}_{3}$, presented the best $\mathrm{IC}_{50}$ values for amastigote form, suggesting that the presence of hydrogen bonds donors in the structure may be of interest for improving the biological activity in the amastigote form.

When we compare the trypanocidal activity in amastigote, the cyclic 4-thiazolidinone derivatives $2 \mathrm{~g}\left(\mathrm{IC}_{50}=12.2 \mu \mathrm{M}\right)$ and $2 \mathbf{h}\left(\mathrm{IC}_{50}=2.4 \mu \mathrm{M}\right)$ were about 4 and 21-folds respectively more active than intermediate compound $\mathbf{1 b}\left(\mathrm{IC}_{50}=51.1 \mu \mathrm{M}\right)$. The same trend was observed to compound $2 \mathbf{p}\left(\mathrm{IC}_{50}=48.5 \mu \mathrm{M}\right)$ approximately 2 -folds more potent than intermediate $1 \mathrm{c}\left(\mathrm{IC}_{50}=89.1 \mu \mathrm{M}\right)$. 
In general, the compounds substituted at the N3 position of the 4-thiazolidinone ring with methyl, for the sub-series 2 , were active against amastigote form $(\mathbf{2} \mathbf{g}, \mathbf{2} \mathbf{h}, \mathbf{2} \mathbf{j}, \mathbf{2 k})$. It is interesting to note that, in contrast to our previous work [10], the 4-thiazolidinones of the present work, with phenyl in the $\mathrm{N} 3$ position were not the most active, with the exception of compound $\mathbf{2 n}\left(\mathrm{IC}_{50 \text { trypo }}=3.7 \mu \mathrm{M}\right)$, which has a methyl group in $\mathrm{C} 5$ of the heterocyclic ring.

Described by [23], within the class of drugs that present halogen atom in their structure, those that possess a fluoride, are in greater quantity since the fluorination changes the physical, chemical and conformational parameters. This feature could eventually result in optimized pharmacological properties. The fluorine chemistry provides good opportunities for enhancing the binding affinity of potential drug candidates. These features have made the trifluoromethyl $\left(\mathrm{CF}_{3}\right)$ useful chemical groups in the contemporary drug design [27]. Within this observation, we can say that the molecules which present trifluoromethyl $\left(\mathrm{CF}_{3}\right)$ group in their structure (1d-e and $\left.\mathbf{3 a - j}\right)$, were not the most active, as expected when compared to the series presenting the halogen bromine (1a-c and 2a-r).

In the sub-series 3 , five compounds were active against trypomastigote form: $3 \mathbf{b}\left(\mathrm{IC}_{50}=61.9 \mu \mathrm{M}\right), 3 \mathbf{c}\left(\mathrm{IC}_{50}=22.4 \mu \mathrm{M}\right), 3 \mathbf{d}$ $\left(\mathrm{IC}_{50}=7.8 \mu \mathrm{M}\right), \mathbf{3 e}\left(\mathrm{IC}_{50}=39.3 \mu \mathrm{M}\right)$ and $\mathbf{3 j}\left(\mathrm{IC}_{50}=59.3 \mu \mathrm{M}\right)$, with highlight 3d compound. In the amastigote form, three compounds were active: $\mathbf{3 a}$ $\left(\mathrm{IC}_{50}=43.2 \mu \mathrm{M}\right), 3 \mathbf{c}\left(\mathrm{IC}_{50}=121.8 \mu \mathrm{M}\right)$ and $\mathbf{3 j}\left(\mathrm{IC}_{50}=22.4 \mu \mathrm{M}\right)$. Contrary to

Table 1. Determination of cytotoxicity in T. cruzi and fibroblast cells

\begin{tabular}{|c|c|c|c|c|c|c|c|c|c|}
\hline Cpd & $\mathbf{R}_{1}$ & $\mathbf{R}_{2}$ & $\mathbf{R}_{3}$ & $\mathbf{R}_{4}$ & $\begin{array}{c}\text { Epimastigote } \mathrm{IC}_{50} \\
{[\mu \mathrm{M}]^{1}}\end{array}$ & Trypomastigote $\mathrm{IC}_{50}[\mu \mathrm{M}]^{2}$ & $\begin{array}{c}\text { Amastigote } \mathrm{IC}_{50} \\
{[\mu \mathrm{M}]^{3}}\end{array}$ & $\begin{array}{c}\text { Fibroblast } \mathrm{CC}_{50} \\
{[\mu \mathrm{M}]}\end{array}$ & SI \\
\hline $1 \mathrm{a}$ & $3-\mathrm{Br}$ & Et & $\mathrm{H}$ & - & 28.7 & 31.8 & 5.7 & 70.1 & 12.2 \\
\hline $1 b$ & $3-\mathrm{Br}$ & Et & $\mathrm{Me}$ & - & ND & 5.0 & 51.1 & 267.5 & 5.2 \\
\hline $1 \mathrm{c}$ & $3-\mathrm{Br}$ & Et & $\mathrm{Ph}$ & - & 6.8 & 2.3 & 89.1 & 110.7 & 1.2 \\
\hline 1d & $4-\mathrm{CF}_{3}$ & $\mathrm{H}$ & $\mathrm{H}$ & - & ND & 20.2 & $<10.11$ & 80.89 & $>8$ \\
\hline $1 \mathrm{e}$ & $4-\mathrm{CF}_{3}$ & $\mathrm{H}$ & $\mathrm{Me}$ & - & ND & 191.4 & - & - & Inactive \\
\hline 1f & $4-\mathrm{CF}_{3}$ & $\mathrm{H}$ & $\mathrm{Ph}$ & - & 20.0 & 13.8 & 45.77 & 61.85 & 1.4 \\
\hline $2 a$ & $3-\mathrm{Br}$ & Et & $\mathrm{H}$ & $\mathrm{H}$ & 82.6 & 146.9 & - & - & Inactive \\
\hline $2 b$ & $3-\mathrm{Br}$ & Et & $\mathrm{H}$ & $\mathrm{Me}$ & ND & 33.7 & 80.2 & 235.9 & 2.9 \\
\hline $2 \mathrm{c}$ & $3-\mathrm{Br}$ & Et & $\mathrm{H}$ & Et & 66.8 & 23.8 & - & - & Inactive \\
\hline 2d & $3-\mathrm{Br}$ & Et & $\mathrm{H}$ & $i$-propyl & ND & 8.1 & - & - & Inactive \\
\hline $2 e$ & $3-\mathrm{Br}$ & Et & $\mathrm{H}$ & $d i \mathrm{Me}$ & 65.2 & 89.0 & 13.3 & $<226.6^{\mathrm{ii}}$ & $<17$ \\
\hline $2 f$ & $3-\mathrm{Br}$ & Et & $\mathrm{H}$ & $\mathrm{Ph}$ & 140.7 & 17.8 & 89.5 & 199.4 & 2.2 \\
\hline $2 \mathrm{~g}$ & $3-\mathrm{Br}$ & Et & $\mathrm{Me}$ & $\mathrm{H}$ & ND & 23.7 & 12.2 & 117.9 & 9.6 \\
\hline $2 \mathrm{~h}$ & $3-\mathrm{Br}$ & Et & $\mathrm{Me}$ & $\mathrm{Me}$ & ND & 18.8 & 2.4 & 56.6 & 23 \\
\hline $2 \mathrm{i}$ & $3-\mathrm{Br}$ & Et & $\mathrm{Me}$ & Et & ND & 55.5 & - & - & Inactive \\
\hline $2 \mathrm{j}$ & $3-\mathrm{Br}$ & Et & $\mathrm{Me}$ & $i$-propyl & 46.0 & 113.9 & 79.5 & $<524.8^{\text {iv }}$ & $<6.6$ \\
\hline $2 k$ & $3-\mathrm{Br}$ & Et & $\mathrm{Me}$ & $d i \mathrm{Me}$ & 69.6 & 46.3 & 175.7 & 217.9 & 1.2 \\
\hline 21 & $3-\mathrm{Br}$ & Et & $\mathrm{Me}$ & $\mathrm{Ph}$ & 119.7 & 7.9 & - & - & Inactive \\
\hline $2 m$ & $3-\mathrm{Br}$ & Et & $\mathrm{Ph}$ & $\mathrm{H}$ & 78.0 & 15.3 & - & - & Inactive \\
\hline $2 n$ & $3-\mathrm{Br}$ & Et & $\mathrm{Ph}$ & $\mathrm{Me}$ & ND & 3.7 & - & - & Inactive \\
\hline 20 & $3-\mathrm{Br}$ & Et & $\mathrm{Ph}$ & Et & 42.2 & 60.1 & - & - & Inactive \\
\hline $2 p$ & $3-\mathrm{Br}$ & Et & $\mathrm{Ph}$ & $i$-propyl & ND & ND & 48.5 & $<112.8^{\mathrm{i}}$ & $<2,3$ \\
\hline $2 q$ & $3-\mathrm{Br}$ & Et & $\mathrm{Ph}$ & $d i \mathrm{Me}$ & 12.4 & 50.3 & 168.7 & $>186.4^{\mathrm{iii}}$ & $>1.1$ \\
\hline $2 r$ & $3-\mathrm{Br}$ & Et & $\mathrm{Ph}$ & $\mathrm{Ph}$ & ND & 53 & - & - & Inactive \\
\hline $3 a$ & $4-\mathrm{CF}_{3}$ & $\mathrm{H}$ & $\mathrm{H}$ & $\mathrm{Ph}$ & ND & ND & 43.2 & 55 & 1.3 \\
\hline $3 b$ & $4-\mathrm{CF}_{3}$ & $\mathrm{H}$ & $\mathrm{H}$ & $\mathrm{Me}$ & ND & 61.9 & - & - & Inactive \\
\hline $3 c$ & $4-\mathrm{CF}_{3}$ & $\mathrm{H}$ & $\mathrm{H}$ & $\mathrm{H}$ & ND & 22.4 & 121.8 & 139.2 & 1.1 \\
\hline 3d & $4-\mathrm{CF}_{3}$ & $\mathrm{H}$ & $\mathrm{H}$ & Et & ND & 7.8 & - & - & Inactive \\
\hline $3 e$ & $4-\mathrm{CF}_{3}$ & $\mathrm{H}$ & $\mathrm{H}$ & $i$-propyl & ND & 39.3 & - & - & Inactive \\
\hline $3 f$ & $4-\mathrm{CF}_{3}$ & $\mathrm{H}$ & $\mathrm{Me}$ & $\mathrm{Ph}$ & ND & ND & - & - & Inactive \\
\hline $3 g$ & $4-\mathrm{CF}_{3}$ & $\mathrm{H}$ & $\mathrm{Me}$ & $\mathrm{Me}$ & ND & ND & - & - & Inactive \\
\hline $3 \mathrm{~h}$ & $4-\mathrm{CF}_{3}$ & $\mathrm{H}$ & $\mathrm{Me}$ & $\mathrm{H}$ & ND & ND & - & - & Inactive \\
\hline $3 \mathbf{i}$ & $4-\mathrm{CF}_{3}$ & $\mathrm{H}$ & $\mathrm{Me}$ & Et & ND & ND & - & - & Inactive \\
\hline $3 \mathbf{j}$ & $4-\mathrm{CF}_{3}$ & $\mathrm{H}$ & $\mathrm{Me}$ & $i$-propyl & 22.4 & 59.3 & 22.4 & 58.2 & 2.6 \\
\hline BZD & - & - & - & - & 48.8 & 6.3 & 3.8 & 2381 & 625 \\
\hline
\end{tabular}

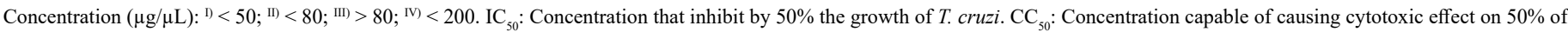
mammalian cells, $\mathrm{CC}_{50}$ and $\mathrm{IC}_{50}$ values were calculated using concentrations in triplicate and experiment was repeated, only values with a standard deviation $<10 \%$ mean were considered. $\mathrm{SI}^{[1]}$ (Selectivity Index): $\mathrm{CC}_{50}$ of mammalian cells / $\mathrm{IC}_{50}$ T. cruzi, BZD: Benznidazole; Inactive: Compound was not active at any tested dose 
series 2, structural characteristic is a methyl in N3 is not beneficial for series 3. The sub-series 2 had the most active compounds substituted in $\mathrm{N} 3$ by a methyl, generally, the most active compound being $\mathbf{2 h}$ (Table 1 ).

Regarding the 1,3-thiazole series, three compounds had lower $\mathrm{IC}_{50}$ values for the amastigote form of $T$. cruzi, compounds $\mathbf{4 b}\left(\mathrm{IC}_{50}\right.$ $=9.9 \mu \mathrm{M}), 4 \mathbf{d}\left(\mathrm{IC}_{50}=5.3 \mu \mathrm{M}\right)$ and $4 \mathbf{h}\left(\mathrm{IC}_{50}=8.9 \mu \mathrm{M}\right)$, they have very electronegative groups attached to the aromatic ring bound to the 1,3-thiazole as a characteristic, however, all compounds presented a very low selectivity index (Table 2). Two of these compounds (4d and 4h) have in common the presence of two chlorines in the aromatic ring bound to the 1,3-thiazole. One at 2 and 4 positions (4d) and the other at 3 and 4 positions (4h), which may indicate that di-substitution with halogens in the aromatic ring may be beneficial for anti-T. cruzi activity, this data corroborates with that recently observed by 10,26 .

Figure 3 below summarizes the pharmacological structure-activity relationships observed in this work.

\section{Physicochemical properties}

We also evaluated the physicochemical properties to determine if they are compliant with the Lipinski's rule $[28,29]$. This rule has important determinants to providing better pharmacokinetics and analyses promising future drug development. For this purpose, physicochemical and ADME properties were calculated using the SwissADME (a free web tool to evaluate pharmacokinetics, drug-

Table 2. Determination of cytotoxicity in T. cruzi and fibroblast cells

\begin{tabular}{|c|c|c|c|c|c|c|c|c|}
\hline Cpd & $\mathbf{R}_{1}$ & $\mathbf{R}_{2}$ & $\mathbf{R}_{3}$ & $\begin{array}{c}\text { Epimastigote }_{[\mu \mathrm{M}]_{50}} \\
{[\mu}\end{array}$ & $\begin{array}{c}\text { Trypomastigote } \\
\text { IC }_{50}[\mu \mathrm{M}]^{2}\end{array}$ & $\begin{array}{c}\text { Amastigote } \mathrm{IC}_{50} \\
{[\mu \mathrm{M}]^{3}}\end{array}$ & $\begin{array}{c}\text { Fibroblast } \mathrm{CC}_{50} \\
{[\mu \mathrm{M}]}\end{array}$ & SI \\
\hline $4 a$ & $\mathrm{H}$ & $\mathrm{Ph}$ & $\mathrm{H}$ & 24.3 & 83.06 & - & - & Inactive \\
\hline $4 b$ & $\mathrm{H}$ & $4-\mathrm{NO}_{2}-\mathrm{Ph}$ & $\mathrm{H}$ & 79.1 & 71.75 & 9.93 & 25.48 & 2.6 \\
\hline $4 c$ & $\mathrm{H}$ & $3-\mathrm{NO}_{2}-\mathrm{Ph}$ & $\mathrm{H}$ & 32.7 & 80.87 & 13.50 & 50.97 & 3.8 \\
\hline $4 d$ & $\mathrm{H}$ & 2,4-diCl-Ph & $\mathrm{H}$ & 10.6 & 53.84 & 5.28 & 12.01 & 2.3 \\
\hline $4 e$ & $\mathrm{H}$ & 4-MeO-Ph & $\mathrm{H}$ & 6.9 & 9.65 & 52.99 & $>105.99$ & $>2$ \\
\hline $4 f$ & $\mathrm{H}$ & 4-Cl-Ph & $\mathrm{H}$ & 25.0 & 42.76 & 19.64 & $>209.53$ & $>10.7$ \\
\hline $4 \mathrm{~g}$ & $\mathrm{H}$ & 4-Br-Ph & $\mathrm{H}$ & 8.5 & 80.33 & 17.82 & 46.92 & 2.6 \\
\hline $4 h$ & $\mathrm{H}$ & 3,4-diCl-Ph & $\mathrm{H}$ & 29.6 & 40.75 & 8.88 & 24.02 & 2.7 \\
\hline $4 i$ & $\mathrm{H}$ & $\mathrm{Ph}$ & $\mathrm{Me}$ & 10.9 & 79.36 & - & - & Inactive \\
\hline $4 j$ & $\mathrm{H}$ & 1-Naph & $\mathrm{H}$ & 24.4 & 88.70 & - & - & Inactive \\
\hline $4 k$ & $\mathrm{H}$ & 4-Me-Ph & $\mathrm{H}$ & 27.5 & 78.53 & - & - & Inactive \\
\hline 41 & $\mathrm{H}$ & 4-F-Ph & $\mathrm{H}$ & 10.6 & 32.98 & 22.71 & 54.74 & 2.4 \\
\hline $4 m$ & $\mathrm{Me}$ & 4-MeO-Ph & $\mathrm{H}$ & 18.6 & 57.52 & 51.09 & $>51.09$ & $>1$ \\
\hline $4 n$ & $\mathrm{Me}$ & $4-\mathrm{NO}_{2}-\mathrm{Ph}$ & $\mathrm{H}$ & 83.7 & 169.66 & 49.21 & $>196.86$ & $>4$ \\
\hline 40 & $\mathrm{Me}$ & 2,4-diCl-Ph & $\mathrm{H}$ & NT & NT & 11.62 & $<22.24$ & $<1.9$ \\
\hline $4 p$ & $\mathrm{Ph}$ & 2,4-diCl-Ph & $\mathrm{H}$ & NT & NT & 10.11 & $<20.22$ & $<2$ \\
\hline $4 q$ & $\mathrm{Ph}$ & 4-MeO-Ph & $\mathrm{H}$ & NT & NT & - & - & Inactive \\
\hline $4 r$ & $\mathrm{Ph}$ & 4-Cl-Ph & $\mathrm{H}$ & NT & NT & - & - & Inactive \\
\hline BZD & - & - & - & 48.8 & 6.3 & 3.8 & 2381 & 626.6 \\
\hline
\end{tabular}

Concentration $(\mu \mathrm{g} / \mu \mathrm{L}):{ }^{\mathrm{I}}<50 ;{ }^{\text {II) }}<80$; III) $>80$; ${ }^{\text {IV) }}<200$. $\mathrm{IC}_{50}$ : Concentration that inhibit by $50 \%$ the growth of $T$. cruzi, $\mathrm{CC}_{50}$ : Concentration capable of causing cytotoxic effect on $50 \%$ of mammalian cells, $\mathrm{CC}_{50}$ and $\mathrm{IC}_{50}$ values were calculated using concentrations in triplicate and experiment was repeated, only values with a standard deviation $<10 \%$ mean were considered. $\mathrm{SI}^{[1]}$ (Selectivity Index): $\mathrm{CC}_{50}$ of mammalian cells / $\mathrm{IC}_{50}$ T. cruzi

BZD: Benznidazole; Inactive: Compound was not active at any tested dose

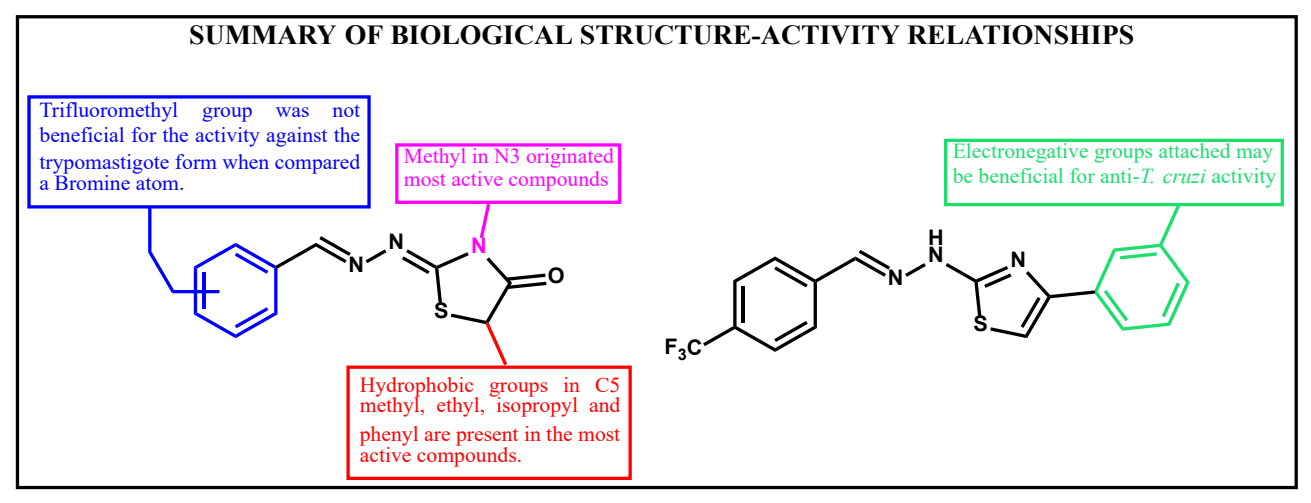

Figure 3. Below summarizes the pharmacological structure-activity relationships observed in this work 
likeness and medicinal chemistry friendliness of small molecules). Compound obeying at least three of the four criteria are considered to adhere the Lipinski Rule [29]. All synthesized compounds are compatible with Lipinski Rule. Another interesting property is the number of rotatable bonds and the polar surface area (PSA). A large number of rotatable bonds $(\geq 10)$ has been associated with poor oral bioavailability [30]. Compounds with a low PSA ( $\leq 140 \AA 22)$ tend to have higher oral bioavailability [30,31]. All synthesized compounds have appropriate PSA and number of rotatable bonds (Table 3 and Table 4).

As demonstrated in Table 5, the most active compounds shown variable permeability based on gastrointestinal absorption (GI), according to the BOILED-Egg predictive model (Brain Or IntestinaL EstimateD permeation method). Three compounds showed high gastrointestinal absorption (1a, $\mathbf{2 h}$ and $\mathbf{2 n}$ ). With respect to oral bioavailability, it's expected 0.55 of the probability of oral bioavailability score $>10 \%$ in the rat for all compounds, similar to BZD. All these data, suggests a good in silico drug-likeness profile and great chemical stabilities for all compounds synthesized.

\section{Conclusion}

This study has synthesized, characterized and identified 46 new heterocyclic compounds, based on previous results. These compounds were assayed against epimastigote, trypomastigote, and amastigote forms of T. cruzi, as well as their toxicity in L929 fibroblasts. For epimastigote form, the most active compound was $4 \mathbf{e}$. Towards trypomastigote and amastigote forms of T. cruzi, the most active heterocycle compounds identified in this study were $\mathbf{2 n}$ (most active against trypomastigote form) and $\mathbf{2 h}$ (most active against amastigote form). The findings of this research provide insights into valuable strategies of synthesis and Structure-Activity relationships (SAR) for the planning of new anti- $T$. cruzi drugs candidates.

\section{Experimental}

\section{General}

Most the chemicals were purchased from Sigma-Aldrich (St. Louis, USA), Merck (Berlin, Germany) or Alfa-Aesar (Massachusetts, USA). Reactions in ultrasound bath were performed in a Unique EM-804 TGR instrument, with a frequency of $40 \mathrm{kHz}$ and a nominal power of $180 \mathrm{~W}$, without external heating. Precoated aluminum sheets (silica gel $60 \mathrm{~F}_{254}$, Merck) were used for thin layer chromatography (TLC) and spots were visualized under UV light. IR spectra in $\mathrm{KBr}$ pellets were acquired at Bruker FT-IR spectrophotometer. ${ }^{1} \mathrm{H}$ and ${ }^{13} \mathrm{C}$ NMR were recorded on a UnityPlus $400 \mathrm{MHz}$ and Bruker AMX-300 $\mathrm{MHz}$ spectrometer, using DMSO- $\mathrm{d}_{6}$ as a solvent and tetramethylsilane (TMS) as the internal standard. Splitting patterns were defined as s,

Table 3. Physicochemical property profile of thiazolidinone derivatives, calculated by Property Calculator (https://mcule.com/apps/property-calculator/)

\begin{tabular}{|c|c|c|c|c|c|c|c|c|c|c|c|}
\hline Cpd & $\mathbf{R}_{1}$ & $\mathbf{R}_{2}$ & $\mathbf{R}_{3}$ & $\mathbf{R}_{4}$ & $\begin{array}{c}\text { MW } \\
(\mathrm{g} / \mathrm{mol}) \\
<\mathbf{5 0 0}\end{array}$ & $\underset{<5}{\log P_{0} / w}$ & $\begin{array}{c}\text { H-bond donors } \\
<5\end{array}$ & $\begin{array}{c}\text { H-bond acceptors } \\
<\mathbf{1 0}\end{array}$ & $\begin{array}{c}\text { Violation Lipinski } \\
\text { Rule of } 5\end{array}$ & $\begin{array}{c}\text { Rotatable bonds } \\
<\mathbf{1 0}\end{array}$ & $\begin{array}{c}* \text { PSA } \\
\left(\AA^{2}\right) \\
\leq 140\end{array}$ \\
\hline $1 \mathrm{a}$ & $3-\mathrm{Br}$ & Et & $\mathrm{H}$ & - & 258.14 & 2.71 & 2 & 3 & 0 & 4 & 82.50 \\
\hline $1 b$ & $3-\mathrm{Br}$ & Et & $\mathrm{Me}$ & - & 272.17 & 2.66 & 2 & 3 & 0 & 5 & 68.51 \\
\hline $1 \mathrm{c}$ & $3-\mathrm{Br}$ & Et & $\mathrm{Ph}$ & - & 334.24 & 4.23 & 2 & 3 & 0 & 6 & 68.51 \\
\hline 1d & $4-\mathrm{CF}_{3}$ & $\mathrm{H}$ & $\mathrm{H}$ & - & 247.24 & 2.96 & 2 & 3 & 0 & 4 & 82.50 \\
\hline $1 \mathrm{e}$ & $4-\mathrm{CF}_{3}$ & $\mathrm{H}$ & $\mathrm{Me}$ & - & 261.27 & 2.91 & 2 & 3 & 0 & 5 & 68.51 \\
\hline $2 a$ & $3-\mathrm{Br}$ & Et & $\mathrm{H}$ & $\mathrm{H}$ & 326.21 & 3.11 & 1 & 4 & 0 & 3 & 79.12 \\
\hline $2 \mathbf{b}$ & $3-\mathrm{Br}$ & $\mathrm{Et}$ & $\mathrm{H}$ & $\mathrm{Me}$ & 340.24 & 3.50 & 1 & 4 & 0 & 3 & 79.12 \\
\hline $2 c$ & $3-\mathrm{Br}$ & Et & $\mathrm{H}$ & Et & 354.27 & 3.89 & 1 & 4 & 0 & 4 & 79.12 \\
\hline $2 d$ & $3-\mathrm{Br}$ & Et & $\mathrm{H}$ & $i$-propyl & 368.29 & 4.14 & 1 & 4 & 0 & 4 & 79.12 \\
\hline $2 \mathrm{e}$ & $3-\mathrm{Br}$ & Et & $\mathrm{H}$ & $d i \mathrm{Me}$ & 354.27 & 3.88 & 1 & 4 & 0 & 3 & 79.12 \\
\hline $2 f$ & $3-\mathrm{Br}$ & Et & $\mathrm{H}$ & $\mathrm{Ph}$ & 402.31 & 4.85 & 1 & 4 & 0 & 4 & 79.12 \\
\hline $2 \mathrm{~g}$ & $3-\mathrm{Br}$ & Et & $\mathrm{Me}$ & $\mathrm{H}$ & 340.24 & 3.06 & 0 & 4 & 0 & 3 & 70.33 \\
\hline $2 \mathrm{~h}$ & $3-\mathrm{Br}$ & Et & $\mathrm{Me}$ & $\mathrm{Me}$ & 354.27 & 3.45 & 0 & 4 & 0 & 3 & 70.33 \\
\hline $2 \mathbf{i}$ & $3-\mathrm{Br}$ & $\mathrm{Et}$ & $\mathrm{Me}$ & Et & 368.29 & 3.84 & 0 & 4 & 0 & 4 & 70.33 \\
\hline $2 \mathrm{j}$ & $3-\mathrm{Br}$ & Et & $\mathrm{Me}$ & $i$-propyl & 382.32 & 4.09 & 0 & 4 & 0 & 4 & 70.33 \\
\hline $2 k$ & $3-\mathrm{Br}$ & Et & $\mathrm{Me}$ & $d i \mathrm{Me}$ & 368.29 & 4.02 & 0 & 4 & 0 & 3 & 70.33 \\
\hline 21 & $3-\mathrm{Br}$ & Et & $\mathrm{Me}$ & $\mathrm{Ph}$ & 416.34 & 4.80 & 0 & 4 & 0 & 4 & 70.33 \\
\hline $2 m$ & $3-\mathrm{Br}$ & Et & $\mathrm{Ph}$ & $\mathrm{H}$ & 402.31 & 4.76 & 0 & 4 & 0 & 4 & 70.33 \\
\hline $2 n$ & $3-\mathrm{Br}$ & Et & $\mathrm{Ph}$ & $\mathrm{Me}$ & 416.34 & 5.15 & 0 & 4 & 1 & 4 & 70.33 \\
\hline 20 & $3-\mathrm{Br}$ & $\mathrm{Et}$ & $\mathrm{Ph}$ & Et & 430.36 & 5.54 & 0 & 4 & 1 & 5 & 70.33 \\
\hline $2 p$ & $3-\mathrm{Br}$ & Et & $\mathrm{Ph}$ & $i$-propyl & 444.39 & 5.79 & 0 & 4 & 1 & 5 & 70.33 \\
\hline $2 q$ & $3-\mathrm{Br}$ & Et & $\mathrm{Ph}$ & $d i \mathrm{Me}$ & 430.36 & 5.54 & 0 & 4 & 1 & 4 & 70.33 \\
\hline $2 r$ & $3-\mathrm{Br}$ & Et & $\mathrm{Ph}$ & $\mathrm{Ph}$ & 478.41 & 6.51 & 0 & 4 & 1 & 5 & 70.33 \\
\hline $\mathbf{3 a}$ & $4-\mathrm{CF}_{3}$ & $\mathrm{H}$ & $\mathrm{H}$ & $\mathrm{Ph}$ & 363.36 & 4.33 & 1 & 4 & 0 & 4 & 79.12 \\
\hline $\mathbf{3 b}$ & $4-\mathrm{CF}_{3}$ & $\mathrm{H}$ & $\mathrm{H}$ & $\mathrm{Me}$ & 301.29 & 2.98 & 1 & 4 & 0 & 3 & 79.12 \\
\hline $3 c$ & $4-\mathrm{CF}_{3}$ & $\mathrm{H}$ & $\mathrm{H}$ & $\mathrm{H}$ & 287.26 & 2.59 & 1 & 4 & 0 & 3 & 79.12 \\
\hline $3 d$ & $4-\mathrm{CF}_{3}$ & $\mathrm{H}$ & $\mathrm{H}$ & Et & 315.32 & 3.36 & 1 & 4 & 0 & 4 & 79.12 \\
\hline $3 e$ & $4-\mathrm{CF}_{3}$ & $\mathrm{H}$ & $\mathrm{H}$ & $i$-propyl & 329.34 & 3.61 & 1 & 4 & 0 & 4 & 79.12 \\
\hline $3 f$ & $4-\mathrm{CF}_{3}$ & $\mathrm{H}$ & $\mathrm{Me}$ & $\mathrm{Ph}$ & 377.39 & 4.28 & 0 & 4 & 0 & 4 & 70.33 \\
\hline $3 g$ & $4-\mathrm{CF}_{3}$ & $\mathrm{H}$ & $\mathrm{Me}$ & $\mathrm{Me}$ & 315.32 & 2.93 & 0 & 4 & 0 & 3 & 70.33 \\
\hline $3 \mathbf{h}$ & $4-\mathrm{CF}_{3}$ & $\mathrm{H}$ & $\mathrm{Me}$ & $\mathrm{H}$ & 301.29 & 2.54 & 0 & 4 & 0 & 3 & 70.33 \\
\hline $3 \mathbf{i}$ & $4-\mathrm{CF}_{3}$ & $\mathrm{H}$ & $\mathrm{Me}$ & Et & 329.34 & 3.32 & 0 & 4 & 0 & 4 & 70.33 \\
\hline $3 \mathbf{j}$ & $4-\mathrm{CF}_{3}$ & $\mathrm{H}$ & $\mathrm{Me}$ & $i$-propyl & 343.37 & 3.56 & 0 & 4 & 0 & 4 & 70.33 \\
\hline
\end{tabular}


Table 4. Physicochemical property profile of thiazole derivatives, calculated by Property Calculator (https://mcule.com/apps/property-calculator)

\begin{tabular}{|c|c|c|c|c|c|c|c|c|c|c|}
\hline Cpd & $\mathbf{R} 1$ & $\mathbf{R 2}$ & $\mathbf{R 3}$ & $\begin{array}{c}\text { MW } \\
(\mathrm{g} / \mathbf{m o l}) \\
<500\end{array}$ & $\begin{array}{c}\log P o / w \\
<5\end{array}$ & $\begin{array}{c}\text { H-bond donors } \\
<5\end{array}$ & $\begin{array}{l}\text { H-bond } \\
\text { acceptors } \\
\quad<10\end{array}$ & $\begin{array}{l}\text { Violation } \\
\text { Lipinski } \\
\text { Rule of } 5\end{array}$ & $\begin{array}{c}\text { Rotatable bonds } \\
<10\end{array}$ & $\begin{array}{c}* \text { PSA } \\
\left(\AA^{2}\right) \\
\leq 140\end{array}$ \\
\hline $1 d$ & $\mathrm{H}$ & - & - & 247.24 & 2.06 & 2 & 3 & 0 & 4 & 82.50 \\
\hline $1 e$ & $\mathrm{Me}$ & - & - & 261.27 & 2.91 & 2 & 3 & 0 & 5 & 68.51 \\
\hline 1f & $\mathrm{Ph}$ & - & - & 323.34 & 4.49 & 2 & 3 & 0 & 6 & 68.51 \\
\hline $4 a$ & $\mathrm{H}$ & $\mathrm{Ph}$ & $\mathrm{H}$ & 349.38 & 4.80 & 1 & 3 & 0 & 5 & 65.52 \\
\hline $4 b$ & $\mathrm{H}$ & $4-\mathrm{NO}_{2}-\mathrm{Ph}$ & $\mathrm{H}$ & 392.36 & 5.78 & 1 & 6 & 1 & 6 & 111.34 \\
\hline $4 c$ & $\mathrm{H}$ & $3-\mathrm{NO}_{2}-\mathrm{Ph}$ & $\mathrm{H}$ & 392.36 & 5.78 & 1 & 6 & 1 & 6 & 111.34 \\
\hline $4 d$ & $\mathrm{H}$ & 2,4-diCl-Ph & $\mathrm{H}$ & 416.25 & 6.00 & 1 & 3 & 1 & 5 & 65.52 \\
\hline $4 e$ & $\mathrm{H}$ & 4-MeO-Ph & $\mathrm{H}$ & 377.39 & 4.71 & 1 & 4 & 0 & 6 & 74.75 \\
\hline $4 f$ & $\mathrm{H}$ & 4-Cl-Ph & $\mathrm{H}$ & 381.80 & 5.35 & 1 & 3 & 1 & 5 & 65.52 \\
\hline $4 \mathrm{~g}$ & $\mathrm{H}$ & 4-Br-Ph & $\mathrm{H}$ & 426.26 & 5.46 & 1 & 3 & 1 & 5 & 65.52 \\
\hline $4 h$ & $\mathrm{H}$ & 3,4-diCl-Ph & $\mathrm{H}$ & 416.25 & 6.00 & 1 & 3 & 1 & 5 & 65.52 \\
\hline $4 i$ & $\mathrm{H}$ & $\mathrm{Ph}$ & $\mathrm{Me}$ & 361.39 & 5.01 & 1 & 3 & 1 & 5 & 65.52 \\
\hline $4 j$ & $\mathrm{H}$ & 1-Naph & $\mathrm{H}$ & 397.42 & 5.85 & 1 & 3 & 1 & 5 & 65.52 \\
\hline $4 k$ & $\mathrm{H}$ & 4-Me-Ph & $\mathrm{H}$ & 361.39 & 5.01 & 1 & 3 & 1 & 5 & 65.52 \\
\hline 41 & $\mathrm{H}$ & 4-F-Ph & $\mathrm{H}$ & 365.35 & 4.84 & 1 & 3 & 0 & 5 & 65.52 \\
\hline $4 m$ & $\mathrm{Me}$ & 4-MeO-Ph & $\mathrm{H}$ & 391.41 & 4.72 & 0 & 4 & 0 & 5 & 67.12 \\
\hline $4 n$ & $\mathrm{Me}$ & $4-\mathrm{NO}_{2}-\mathrm{Ph}$ & $\mathrm{H}$ & 406.38 & 5.14 & 0 & 6 & 1 & 5 & 103.71 \\
\hline 40 & $\mathrm{Me}$ & 2,4-diCl-Ph & $\mathrm{H}$ & 430.27 & 6.01 & 0 & 3 & 1 & 4 & 57.89 \\
\hline $4 p$ & $\mathrm{Ph}$ & 2,4-diCl-Ph & $\mathrm{H}$ & 492.34 & 7.47 & 0 & 3 & 1 & 5 & 57.89 \\
\hline $4 q$ & $\mathrm{Ph}$ & 4-MeO-Ph & $\mathrm{H}$ & 453.48 & 6.17 & 0 & 4 & 1 & 6 & 67.12 \\
\hline $4 r$ & $\mathrm{Ph}$ & 4-Cl-Ph & $\mathrm{H}$ & 457.90 & 6.81 & 0 & 3 & 1 & 5 & 57.89 \\
\hline
\end{tabular}

Table 5. ADME properties of most active compounds

\begin{tabular}{|c|c|c|c|}
\hline Compound & *BBB permeant & **GI absorption \\
\hline $\mathbf{1 a}$ & No & High \\
\hline $\mathbf{2 h}$ & Yes & High \\
\hline $\mathbf{2 n}$ & Yes & High & 0.55 \\
\hline $\mathbf{4 d}$ & No & Low & 0.55 \\
\hline BZD & No & High & 0.55 \\
\hline
\end{tabular}

*BBB - blood-brain barrier. **GI - Gastrointestinal absorption

singlet; $d$, doublet; $t$, triplet; $q$, quartet; $m$, multiplet. Chemical shift values were given in, ppm. DEPT was employed to confirm the carbon assignment. Melting points were measured using capillaries on a Thomas device Hoover.

Synthesis of intermediate thiosemicarbazones. Example for 3-bromophenyl propylidene hydrazine carbothioamide (1a)

In a round bottom flask for $50 \mathrm{~mL}$, the 3-bromophenyl propanone $(0.45 \mathrm{~g}, 2.12 \mathrm{mmol})$ was dissolved in $8 \mathrm{~mL} \mathrm{EtOH}$, following by the addition of catalytic $\mathrm{HCl}$. The flask was placed in an ultrasound bath $(40 \mathrm{kHz}, 180 \mathrm{~W})$ and under sonication, $0.23 \mathrm{~g}(2.12 \mathrm{mmol})$ of thiosemicarbazide was added in the reaction. After $3 \mathrm{~h}$, distilled water was added, and the precipitate formed was cooled at $0^{\circ} \mathrm{C}$ and the precipitate was filtered in a Büchner funnel with a sintered disc filter, washed with ethanol and then dried over $\mathrm{SiO}_{2}$. Colorless crystals were formed in a yield of approximately $70 \%$.

2-(1-(3-bromophenyl)propylidene)hydrazinecarbothioamide (1a)

Yellow crystals; Yield 68\%; m.p. $\left({ }^{\circ} \mathrm{C}\right)$ 140-143; Rf: 0.71 (Hexane/ ethyl acetate 7:3). IR $\left(\mathrm{KBr}, \mathrm{cm}^{-1}\right): 3416(\mathrm{NH}), 3202$ and $3147\left(\mathrm{NH}_{2}\right)$, $1598(\mathrm{C}=\mathrm{N}) .{ }^{1} \mathrm{H}$ NMR $\left(400 \mathrm{MHz}, \mathrm{DMSO}-d_{6}\right), \delta, \mathrm{ppm}: 1.01(\mathrm{t}, J=7.6 \mathrm{~Hz}$, $\left.3 \mathrm{H}, \mathrm{CH}_{3}\right), 2.83\left(\mathrm{q}, J=7.6 \mathrm{~Hz}, 2 \mathrm{H}, \mathrm{CH}_{2}\right), 7.34(\mathrm{t}, J=7.8 \mathrm{~Hz}, 1 \mathrm{H}, \mathrm{Ar}), 7.52$ $(\mathrm{d}, J=7.6 \mathrm{~Hz}, 1 \mathrm{H}, \mathrm{Ar}), 7.83(\mathrm{~d}, J=7.6 \mathrm{~Hz}, 1 \mathrm{H}, \mathrm{Ar}), 8.12(\mathrm{~s}, 1 \mathrm{H}, \mathrm{Ar}), 8.34$ (s, H, NH), $10.32\left(\mathrm{~s}, 2 \mathrm{H}, \mathrm{NH}_{2}\right) .{ }^{13} \mathrm{C}$ NMR (100 MHz, DMSO- $\left.d_{6}\right), \delta$, ppm: $10.8\left(\mathrm{CH}_{3}\right), 19.1\left(\mathrm{CH}_{2}\right), 122.0(\mathrm{CH}, \mathrm{Ar}), 125.7(\mathrm{CH}, \mathrm{Ar}), 129.0(\mathrm{CH}, \mathrm{Ar})$, $130.3(\mathrm{CH}, \mathrm{Ar}), 133.0(\mathrm{CH}, \mathrm{Ar}), 136.2(\mathrm{CH}, \mathrm{Ar}), 150.2(\mathrm{C}=\mathrm{N}), 179.1$ $(\mathrm{C}=\mathrm{S})$.

\section{2-(1-(3-bromophenyl)propylidene)- $N$-methylhydrazinecarbo- thioamide (1b)}

Yellow crystals; Yield 81\%; m.p. $\left({ }^{\circ} \mathrm{C}\right)$ 143-146; Rf: 0.72 (Hexane/ ethyl acetate 8:2). IR $\left(\mathrm{KBr}, \mathrm{cm}^{-1}\right): 3290$ and $3192(\mathrm{NH}), 1551(\mathrm{C}=\mathrm{N}) .{ }^{1} \mathrm{H}$ NMR (400 MHz, DMSO- $\left.d_{6}\right), \delta$, ppm: $1.02\left(\mathrm{t}, J=7.4 \mathrm{~Hz}, 3 \mathrm{H}, \mathrm{CH}_{3}\right), 2.83$ $\left(\mathrm{q}, J=7.4 \mathrm{~Hz}, 2 \mathrm{H}, \mathrm{CH}_{2}\right), 3.45\left(\mathrm{~d}, 3 \mathrm{H}, \mathrm{CH}_{3}-\mathrm{NH}\right), 7.34(\mathrm{t}, J=7.9 \mathrm{~Hz}, 1 \mathrm{H}$, Ar), 7.53 (d, $J=7.8 \mathrm{~Hz}, 1 \mathrm{H}, \mathrm{Ar}), 7.84(\mathrm{~d}, J=8.0 \mathrm{~Hz}, 1 \mathrm{H}, \mathrm{Ar}), 8.12(\mathrm{~s}$, $1 \mathrm{H}, \mathrm{Ar}), 8.51$ (br.s, $1 \mathrm{H}, \mathrm{NH}), 10.42$ (br.s, $1 \mathrm{H}, \mathrm{NH}) .{ }^{13} \mathrm{C} \mathrm{NMR}(100 \mathrm{MHz}$, DMSO-d $\left.)_{6}\right), \delta$, ppm: $\boldsymbol{\delta} 10.7\left(\mathrm{CH}_{3}\right), 19.1\left(\mathrm{CH}_{2}\right), 31.1\left(\mathrm{~N}-\mathrm{CH}_{3}\right), 122.1(\mathrm{CH}$, Ar), 125.7 (BrC, Ar), $127.2(\mathrm{CH}, \mathrm{Ar}), 130.4(\mathrm{CH}, \mathrm{Ar}), 131.7(\mathrm{CH}, \mathrm{Ar})$, $138.8(\mathrm{C}, \mathrm{Ar}), 149.9(\mathrm{C}=\mathrm{N}), 178.6(\mathrm{C}=\mathrm{S})$.

\section{2-(1-(3-bromophenyl)propylidene)- $N$-phenylhydrazine- carbothioamide (1c)}

Yellow crystals; Yield 70\%; m.p. $\left({ }^{\circ} \mathrm{C}\right)$ 150-151; Rf: 0.60 (Hexane/ ethyl acetate 8:2). IR (KBr, cm $\left.{ }^{-1}\right): 3307$ and $2971(\mathrm{NH}), 1522(\mathrm{C}=\mathrm{N}) .{ }^{1} \mathrm{H}$ NMR (400 MHz, DMSO- $d_{6}$ ), $\delta$, ppm: $1.12\left(\mathrm{t}, J=7.4 \mathrm{~Hz}, 3 \mathrm{H}, \mathrm{CH}_{3}\right), 2.90$ 
(q, $\left.J=7.4 \mathrm{~Hz}, 2 \mathrm{H}, \mathrm{CH}_{2}\right), 7.21(\mathrm{t}, J=7.2 \mathrm{~Hz}, 1 \mathrm{H}, \mathrm{Ar}), 7.32(\mathrm{~m}, 3 \mathrm{H}, \mathrm{Ar})$, $7.53(\mathrm{~m}, 3 \mathrm{H}, \mathrm{Ar}), 7.90$ (d, $J=7.6 \mathrm{~Hz}, 1 \mathrm{H}, \mathrm{Ar}), 8.21$ (s, 1H, Ar), 10.12 (s, $1 \mathrm{H}, \mathrm{NH}), 10.73$ (s, $1 \mathrm{H}, \mathrm{ArNH}) .{ }^{13} \mathrm{C}$ NMR $\left(100 \mathrm{MHz}, \mathrm{DMSO}-d_{6}\right), \delta$, ppm: $10.8\left(\mathrm{CH}_{3}\right), 19.4\left(\mathrm{CH}_{2}\right), 122.0(\mathrm{CH}, \mathrm{Ar}), 125.4(\mathrm{CH}, \mathrm{Ar}), 125.9$ (BrC, Ar), $126.1(\mathrm{CH}, \mathrm{Ar}), 128.0(\mathrm{CH}, \mathrm{Ar}), 129.2(\mathrm{CH}, \mathrm{Ar}), 130.3(\mathrm{CH}$, Ar), $131.9(\mathrm{CH}, \mathrm{Ar}), 138.6(\mathrm{C}, \mathrm{Ar}), 139.1(\mathrm{C}-\mathrm{N}, \mathrm{Ar}), 151.1(\mathrm{C}=\mathrm{N}), 177.2$ $(\mathrm{C}=\mathrm{S})$.

\section{4-(trifluoromethyl)phenyl] methylidene\}amino] thiourea (1d)}

White crystals; Yield 85\%; m.p. $\left({ }^{\circ} \mathrm{C}\right)$ 166-170; Rf:0,41 (hexane/ethyl acetate 7:3). IR $\left(\mathrm{KBr}, \mathrm{cm}^{-1}\right): 3272.63(\mathrm{NH}), 1698.36(\mathrm{C}=\mathrm{N}) .{ }^{1} \mathrm{H}$ NMR $\left(400 \mathrm{MHz}, \mathrm{DMSO}-d_{6}\right), \delta$, ppm: 3.35 (s, $\left.2 \mathrm{H}, \mathrm{NH}_{2}\right), 7.67$ (d, $J=7.8 \mathrm{~Hz}$, $2 \mathrm{H}, \mathrm{Ar}), 7.80(\mathrm{~d}, J=8.1 \mathrm{~Hz}, 2 \mathrm{H}, \mathrm{Ar}), 8.30(\mathrm{~s}, 1 \mathrm{H}, \mathrm{HC}=\mathrm{N}), 11.60(\mathrm{~s}, 1 \mathrm{H}$, $\mathrm{NH}) .{ }^{13} \mathrm{C}$ NMR (100 MHz, DMSO- $\left.d_{6}\right), \delta$, ppm: 125.3 (C, Ar), 125.3 (C, Ar), 127.7 (C, Ar), 130.0 (C, Ar), 134.5 (C, Ar), 138.1 (C, Ar), 140.2 $(\mathrm{C}=\mathrm{N}), 178.3(\mathrm{C}=\mathrm{S})$.

\section{3-methyl-1-\{[4-(trifluoromethyl)phenyl]methylidene $\}$} aminothiourea (1e)

White crystals; Yield 94\%; m.p. $\left({ }^{\circ} \mathrm{C}\right)$ 234-236; Rf:0,75 (hexane/ethyl acetate 7:3). IR $\left(\mathrm{KBr}, \mathrm{cm}^{-1}\right): 3158.76(\mathrm{NH}), 1539.93(\mathrm{C}=\mathrm{N}) .{ }^{1} \mathrm{H}$ NMR $\left(400 \mathrm{MHz}, \mathrm{DMSO}-d_{6}\right), \delta$, ppm: $3.02\left(\mathrm{~d}, J=4.2 \mathrm{~Hz}, 3 \mathrm{H}, \mathrm{CH}_{3}\right), 7.76(\mathrm{~d}, J=$ $7.8 \mathrm{~Hz}, 2 \mathrm{H}, \mathrm{Ar}), 8.02(\mathrm{~d}, J=7.5 \mathrm{~Hz}, 2 \mathrm{H}, \mathrm{Ar}), 8.69(\mathrm{~s}, 1 \mathrm{H}, \mathrm{HC}=\mathrm{N}), 11.69$ (s, $1 \mathrm{H}, \mathrm{NH}) .{ }^{13} \mathrm{C}$ NMR $\left(100 \mathrm{MHz}\right.$, DMSO- $\left.d_{6}\right), \delta$, ppm: $30.9\left(\mathrm{CH}_{3}\right), 125.5$ (C, Ar), 127.7 (C, Ar), $138.4(\mathrm{C}, \mathrm{Ar}), 138.8(\mathrm{C}=\mathrm{N}), 177.9(\mathrm{C}=\mathrm{S})$.

Synthesis of aryl-thiazolinones (2a-2r). Example: 3-bromophenyl propylidene hydrazone - 3,5-dimethylthiazolidin4-one: (2h):

In a round bottom flask for $50 \mathrm{~mL}$, was added the compound INT-2 (0.61 g, $2.12 \mathrm{mmol}), 20 \mathrm{~mL}$ of ethanol and anhydrous sodium acetate $(0.71 \mathrm{~g}, 8.28 \mathrm{mmol})$. After heating for about 15 minutes, methyl 2-bromopropionate was added $(0.65 \mathrm{~g}, 4.24 \mathrm{mmol})$ and the reaction was stirred and refluxed $\left(120^{\circ} \mathrm{C}\right)$ for approximately 20 hours (monitored by TLC). The reaction was cooled at $0^{\circ} \mathrm{C}$ for two days and, subsequently, the powder was separated from the supernatant Buchner funnel with a sintered disc filter, washed with ethanol and then transferred to a desiccator under vacuum. There was obtained a yellow coloured powder with a yield of $92 \%$.

2-((1-(3-bromophenyl)propylidene)hydrazono)thiazolidin4-one (2a)

Recrystallization in toluene afforded white crystals, yield $=22 \%$. M.p. $\left({ }^{\circ} \mathrm{C}\right)$ : 142-144. Rf: 0.66 (Toluene/ethyl acetate 7:3). IR (KBr): $3201(\mathrm{NH}), 1601(\mathrm{C}=\mathrm{O}), 1507(\mathrm{C}=\mathrm{N}) \mathrm{cm}^{-1} .{ }^{1} \mathrm{H}$ NMR $(300 \mathrm{MHz}$, DMSO- $\left.d_{6}\right): 0.92\left(\mathrm{t}, J=7.2 \mathrm{~Hz}, 3 \mathrm{H}, \mathrm{CH}_{3}\right), 2.93\left(\mathrm{q}, J=7.2 \mathrm{~Hz}, 2 \mathrm{H}, \mathrm{CH}_{2}\right)$, $3.93\left(\mathrm{~s}, 2 \mathrm{H}, \mathrm{CH}_{2}\right), 7.32(\mathrm{t}, J=7.9 \mathrm{~Hz}, 1 \mathrm{H}, \mathrm{Ar}), 7.64(\mathrm{~d}, J=7.5 \mathrm{~Hz}, 1 \mathrm{H}$, Ar), $7.72(\mathrm{~d}, J=7.5 \mathrm{~Hz}, 1 \mathrm{H}, \mathrm{Ar}), 7.91(\mathrm{~s}, 1 \mathrm{H}, \mathrm{Ar}), 11.92(\mathrm{~s}, 1 \mathrm{H}, \mathrm{NH})$. ${ }^{13} \mathrm{C}$ NMR $\left(75.5 \mathrm{MHz}, \mathrm{DMSO}-d_{6}\right): 11.6\left(\mathrm{CH}_{3}\right), 20.7\left(\mathrm{CH}_{2}\right), 32.8\left(\mathrm{CH}_{2}\right.$, heterocycle), 122.0 ( $\mathrm{CH}, \mathrm{Ar}), 125.6$ (BrC, Ar), 128.9 (CH, Ar), 130.7 $(\mathrm{CH}, \mathrm{Ar}), 132.3(\mathrm{CH}, \mathrm{Ar}), 138.8(\mathrm{C}, \mathrm{Ar}), 163.5(\mathrm{C}=\mathrm{N}), 165.5(\mathrm{~S}-\mathrm{C}=\mathrm{N})$, $173.9(\mathrm{C}=\mathrm{O})$.

2 - ( (1 - (3-bromophenyl) propylidene)hydrazono ) - 5methylthiazolidin-4-one (2b)

The washing in ethanol afforded yellow powders, yield $=49 \%$. M.p. $\left({ }^{\circ} \mathrm{C}\right)$ : 119-121. Rf: 0.68 (Toluene/ethyl acetate 8:2). IR (KBr): 3409 $(\mathrm{NH}), 1722(\mathrm{C}=\mathrm{O}), 1565(\mathrm{C}=\mathrm{N}) \mathrm{cm}^{-1} .{ }^{1} \mathrm{H}$ NMR $\left(300 \mathrm{MHz}, \mathrm{DMSO}-d_{6}\right)$ : $1.02\left(\mathrm{t}, J=7.65 \mathrm{~Hz}, 3 \mathrm{H}, \mathrm{CH}_{3}\right), 1.53\left(\mathrm{~d}, J=6.9 \mathrm{~Hz}, 3 \mathrm{H}, \mathrm{CH}_{3}-\mathrm{C} 5\right), 2.92$ (q, $\left.J=7.7 \mathrm{~Hz}, 2 \mathrm{H}, \mathrm{CH}_{2}\right), 4.14(\mathrm{q}, J=7.3 \mathrm{~Hz}, 1 \mathrm{H}, \mathrm{CH}$ heterocycle), 7.43 $(\mathrm{t}, J=7.95 \mathrm{~Hz}, 1 \mathrm{H}, \mathrm{Ar}), 7.62(\mathrm{~d}, J=9.9 \mathrm{~Hz}, 1 \mathrm{H}, \mathrm{Ar}), 7.84(\mathrm{~d}, J=9.8$ $\mathrm{Hz}, 1 \mathrm{H}, \mathrm{Ar}), 7.92$ (s, 1H, Ar), $11.82(\mathrm{~s}, 1 \mathrm{H}, \mathrm{NH}) .{ }^{13} \mathrm{C}$ NMR $(75.5 \mathrm{MHz}$, DMSO- $\left.d_{6}\right): 11.6\left(\mathrm{CH}_{3}\right), 18.6\left(\mathrm{CH}_{2}\right), 20.6\left(\mathrm{CH}_{3}\right.$, heterocycle $), 41.9(\mathrm{CH}$, heterocycle), $122.0(\mathrm{CH}, \mathrm{Ar}), 125.6(\mathrm{BrC}, \mathrm{Ar}), 126.2(\mathrm{CH}, \mathrm{Ar}), 129.4$ $(\mathrm{CH}, \mathrm{Ar}), 130.8(\mathrm{CH}, \mathrm{Ar}), 133.2(\mathrm{C}, \mathrm{Ar}), 150.6(\mathrm{C}=\mathrm{N}), 163.6(\mathrm{~S}-\mathrm{C}=\mathrm{N})$, $176.7(\mathrm{C}=\mathrm{O})$.

2 - (( 1 - (3 - bromophenyl) propylidene $)$ hydrazono $)-5$ ethylthiazolidin-4-one (2c)

Recrystallization in toluene afforded yellowish crystals, yield = 58\%. M.p. ( $\left.{ }^{\circ} \mathrm{C}\right)$ : 116-118. Rf: 0.70 (Toluene/ethyl acetate 8:2). IR (KBr): $1714(\mathrm{C}=\mathrm{O}), 1613(\mathrm{C}=\mathrm{N}) \mathrm{cm}^{-1} .{ }^{1} \mathrm{H}$ NMR $\left(300 \mathrm{MHz}, \mathrm{DMSO}-d_{6}\right): 0.93$ $\left(\mathrm{m}, 6 \mathrm{H}, \mathrm{CH}_{3}\right), 1.92\left(\mathrm{~m}, 2 \mathrm{H}, \mathrm{CH}_{2}-\mathrm{C} 5\right), 2.94\left(\mathrm{q}, J=7.5 \mathrm{~Hz}, 2 \mathrm{H}, \mathrm{CH}_{2}\right), 4.12$ (q, $J=4.0 \mathrm{~Hz}, 1 \mathrm{H}, \mathrm{CH}$ heterocycle), $7.30(\mathrm{t}, J=7.9 \mathrm{~Hz}, 1 \mathrm{H}, \mathrm{Ar}), 7.63$ $(\mathrm{d}, J=7.8 \mathrm{~Hz}, 1 \mathrm{H}, \mathrm{Ar}), 7.8(\mathrm{~d}, J=7.8 \mathrm{~Hz}, 1 \mathrm{H}, \mathrm{Ar}), 7.92(\mathrm{~s}, 1 \mathrm{H}, \mathrm{Ar}) .{ }^{13} \mathrm{C}$ NMR (75.5 MHz, DMSO- $\left.d_{6}\right): 10.3\left(\mathrm{CH}_{3}\right), 11.6\left(\mathrm{CH}_{3}\right), 20.6\left(\mathrm{CH}_{2}\right), 25.4$ $\left(\mathrm{CH}_{2}\right), 49.2$ (CH heterocycle), $122.0(\mathrm{CH}, \mathrm{Ar}), 125.5$ (BrC, $\left.\mathrm{Ar}\right), 128.8$ $(\mathrm{CH}, \mathrm{Ar}), 130.7(\mathrm{CH}, \mathrm{Ar}), 132.1(\mathrm{CH}, \mathrm{Ar}), 138.9(\mathrm{C}, \mathrm{Ar}), 163.0(\mathrm{C}=\mathrm{N})$, $165.2(\mathrm{~S}-\mathrm{C}=\mathrm{N}), 176.8(\mathrm{C}=\mathrm{O})$.

2 - ( 1 - ( 3 - bromophenyl) propylidene $)$ hidrazono $)$ - 5 isopropilthiazolidin-4-one $(2 \mathrm{~d})$

The washing in ethanol afforded yellow powders, yield $=93 \%$. M.p. $\left({ }^{\circ} \mathrm{C}\right)$ : 135-137. Rf: 0.74 (Toluene/ethyl acetate 8:2). IR (KBr): $3421(\mathrm{NH}), 1708(\mathrm{C}=\mathrm{O}), 1613(\mathrm{C}=\mathrm{N}) \mathrm{cm}^{-1} .{ }^{1} \mathrm{H}$ NMR $(400 \mathrm{MHz}$, DMSO- $\left.d_{6}\right): 0.92(\mathrm{~m}, 9 \mathrm{H}, \mathrm{CH} 3), 2.43(\mathrm{~m}, 1 \mathrm{H}, \mathrm{CH}-\mathrm{C} 5), 2.81$ (q, $J=$ $\left.5.9 \mathrm{~Hz}, 2 \mathrm{H}, \mathrm{CH}_{2}\right), 3.92(\mathrm{~d}, J=3.2 \mathrm{~Hz}, 1 \mathrm{H}, \mathrm{CH}$ heterocycle $), 7.32$ $(\mathrm{t}, J=7.8 \mathrm{~Hz}, 1 \mathrm{H}, \mathrm{Ar}), 7.53(\mathrm{~d}, J=8.4 \mathrm{~Hz}, 1 \mathrm{H}, \mathrm{Ar}), 7.74(\mathrm{~d}, J=$ $7.6 \mathrm{~Hz}, 1 \mathrm{H}, \mathrm{Ar}), 7.92$ (s, $1 \mathrm{H}, \mathrm{Ar}) .{ }^{13} \mathrm{C}$ NMR $\left(100 \mathrm{MHz}, \mathrm{DMSO}-d_{6}\right)$ : $11.5\left(\mathrm{CH}_{3}\right), 16.3\left(\mathrm{CH}_{3}\right), 17.7\left(\mathrm{CH}_{3}\right), 20.3\left(\mathrm{CH}_{2}\right), 21.3(\mathrm{CH}), 56.5$ ( $\mathrm{CH}$ heterocycle), $121.9(\mathrm{CH}, \mathrm{Ar}), 125.1$ (BrC, Ar), $128.4(\mathrm{CH}, \mathrm{Ar})$, 130.5 (CH, Ar), 131.3 (CH, Ar), $139.6(\mathrm{C}, \mathrm{Ar}), 159.5(\mathrm{C}=\mathrm{N}), 160.4$ $(\mathrm{S}-\mathrm{C}=\mathrm{N}), 172.1(\mathrm{C}=\mathrm{O})$.

2-((1 - (3-bromophenyl) propylidene $)$ hidrazono $)-5,5$ dimethylthiazolidin-4-one (2e)

Recrystallization in toluene afforded yellowish crystals, yield = 88\%. M.p. $\left({ }^{\circ} \mathrm{C}\right): 162-164$. Rf: 0.45 (Toluene/ethyl acetate 8:2). IR (KBr): $1712(\mathrm{C}=\mathrm{O}), 1615(\mathrm{C}=\mathrm{N}) \mathrm{cm}^{-1} .{ }^{1} \mathrm{H}$ NMR $\left(400 \mathrm{MHz}, \mathrm{DMSO}-d_{6}\right): 1.12(\mathrm{t}$, $J=7.4 \mathrm{~Hz}, 3 \mathrm{H}, \mathrm{CH} 3), 1.74\left(\mathrm{~s}, 6 \mathrm{H}, \mathrm{CH}_{3}\right), 2.93\left(\mathrm{q}, J=7.4 \mathrm{~Hz}, 2 \mathrm{H}, \mathrm{CH}_{2}\right)$, $7.23(\mathrm{t}, J=6.4 \mathrm{~Hz}, 1 \mathrm{H}, \mathrm{Ar}), 7.54(\mathrm{~d}, J=8.4 \mathrm{~Hz}, 1 \mathrm{H}, \mathrm{Ar}), 7.74(\mathrm{~d}, J=7.6$ $\mathrm{Hz}, 1 \mathrm{H}, \mathrm{Ar}), 7.93$ (s, $1 \mathrm{H}, \mathrm{Ar}) .{ }^{13} \mathrm{C}$ NMR $\left(100 \mathrm{MHz}, \mathrm{DMSO}-d_{6}\right): 11.8$ $\left(\mathrm{CH}_{3}\right), 22.0\left(\mathrm{CH}_{2}\right), 28.0\left(\mathrm{CH}_{3}\right.$ heterocycle $), 28.3\left(\mathrm{CH}_{3}\right.$ heterocycle $), 49.6$ (C, heterocycle), 122.0 (CH, Ar), 122.8 (BrC, Ar), $123.3(\mathrm{CH}, \mathrm{Ar}), 129.9$ $(\mathrm{CH}, \mathrm{Ar}), 130.0(\mathrm{CH}, \mathrm{Ar}), 133.1(\mathrm{C}, \mathrm{Ar}), 161.7(\mathrm{C}=\mathrm{N}), 166.2(\mathrm{~S}-\mathrm{C}=\mathrm{N})$, $175.1(\mathrm{C}=\mathrm{O})$.

\section{2-( ( 1 - (3-bromophenyl) propylidene)hidrazono ) - 5 -} phenylthiazolidin-4-one (2f)

The washing in ethanol afforded yellow powders, yield $=85 \%$. M.p. $\left({ }^{\circ} \mathrm{C}\right): 187-189$. Rf: 0.82 (Toluene/ethyl acetate 8:2). IR (KBr): 1709 $(\mathrm{C}=\mathrm{O}), 1619(\mathrm{C}=\mathrm{N}) \mathrm{cm}^{-1} .{ }^{1} \mathrm{H}$ NMR $\left(400 \mathrm{MHz}, \mathrm{DMSO}-d_{6}\right): 1.02(\mathrm{t}, J$ $\left.=7.4 \mathrm{~Hz}, 3 \mathrm{H}, \mathrm{CH}_{3}\right), 2.93\left(\mathrm{q}, J=7.6 \mathrm{~Hz}, 2 \mathrm{H}, \mathrm{CH}_{2}\right), 5.42(\mathrm{~s}, 1 \mathrm{H}, \mathrm{CH}$ heterocycle), $7.14(\mathrm{~m}, 6 \mathrm{H}, \mathrm{Ar}), 7.63(\mathrm{~d}, J=7.2 \mathrm{~Hz}, 1 \mathrm{H}, \mathrm{Ar}-\mathrm{Br}), 7.75$ (d, $J=7.9 \mathrm{~Hz}, 1 \mathrm{H}, \mathrm{Ar}-\mathrm{Br}), 7.93(\mathrm{~s}, 1 \mathrm{H}, \mathrm{Ar}-\mathrm{Br}) .{ }^{13} \mathrm{C}$ NMR $(100 \mathrm{MHz}$, DMSO- $\left.d_{6}\right): 11.6\left(\mathrm{CH}_{3}\right), 20.7\left(\mathrm{CH}_{2}\right), 51.1(\mathrm{CH}$ heterocycle $), 122.0(\mathrm{CH}$, $\mathrm{Ar}), 125.2(\mathrm{BrC}, \mathrm{Ar}), 125.6(\mathrm{CH}, \mathrm{Ar}), 128.0(\mathrm{CH}, \mathrm{Ar}), 128.1(\mathrm{CH}, \mathrm{Ar})$, $128.4(\mathrm{CH}, \mathrm{Ar}), 128.8$ (CH, Ar), 128.9 (CH, Ar), 130.7 (CH, Ar), 132.3 (C, Ar), $138.7(\mathrm{C}=\mathrm{N}), 163.4(\mathrm{~S}-\mathrm{C}=\mathrm{N}), 175.3(\mathrm{C}=\mathrm{O})$. 
2-((1-(3-bromophenyl) propylidene)hidrazono )-3methylthiazolidin-4-one ( $2 \mathrm{~g})$

The washing in ethanol afforded yellow powders, yield $=74 \%$. M.p. $\left({ }^{\circ} \mathrm{C}\right)$ : 129-131. Rf: 0.72 (Toluene/ethyl acetate 9:1). IR (KBr): $1707(\mathrm{C}=\mathrm{O}), 1628(\mathrm{C}=\mathrm{N}) \mathrm{cm}^{-1} .{ }^{1} \mathrm{H}$ NMR $\left(400 \mathrm{MHz}, \mathrm{DMSO}-d_{6}\right): 1.02$ $\left(\mathrm{t}, J=7.2 \mathrm{~Hz}, 3 \mathrm{H}, \mathrm{CH}_{3}\right), 1.84\left(\mathrm{~m}, 2 \mathrm{H}, \mathrm{CH}_{2}\right), 2.93\left(\mathrm{~s}, \mathrm{CH}_{2}\right.$ heterocycle), $3.34\left(\mathrm{~s}, 3 \mathrm{H}, \mathrm{N}-\mathrm{CH}_{3}\right), 7.42(\mathrm{t}, J=7.8 \mathrm{~Hz}, 1 \mathrm{H}, \mathrm{Ar}), 7.63(\mathrm{~d}, J=7.2 \mathrm{~Hz}$, $1 \mathrm{H}, \mathrm{Ar}), 7.82(\mathrm{~d}, J=7.9 \mathrm{~Hz}, 1 \mathrm{H}, \mathrm{Ar}), 7.93(\mathrm{~s}, 1 \mathrm{H}, \mathrm{Ar}) .{ }^{13} \mathrm{C}$ NMR $(100$ $\left.\mathrm{MHz}, \mathrm{DMSO}-d_{6}\right): 11.9\left(\mathrm{CH}_{3}\right), 20.6\left(\mathrm{CH}_{2}\right), 25.4(\mathrm{CH}$ heterocycle $), 49.2$ $\left(\mathrm{N}-\mathrm{CH}_{3}\right), 121.9(\mathrm{CH}, \mathrm{Ar}), 125.5(\mathrm{BrC}, \mathrm{Ar}), 128.8(\mathrm{CH}, \mathrm{Ar}), 130.7(\mathrm{CH}$, Ar), $132.1(\mathrm{CH}, \mathrm{Ar}), 138.9$ (C, Ar), $163.0(\mathrm{C}=\mathrm{N}), 165.1(\mathrm{~S}-\mathrm{C}=\mathrm{N}), 176.8$ $(\mathrm{C}=\mathrm{O})$.

2-((1-(3-bromophenyl)propylidene)hidrazono)-3,5-dimethylthiazolidin-4-one (2h)

The washing in ethanol afforded yellow powders, yield $=92 \%$. M.p. $\left({ }^{\circ} \mathrm{C}\right): 120-122$. Rf: 0.68 (Toluene/ethyl acetate 8:2). IR (KBr): 1716 $(\mathrm{C}=\mathrm{O}), 1611$ and $1573(\mathrm{C}=\mathrm{N}) \mathrm{cm}^{-1} .{ }^{1} \mathrm{H}$ NMR $\left(300 \mathrm{MHz}, \mathrm{DMSO}-d_{6}\right)$ : $1.02(\mathrm{t}, J=7.6 \mathrm{~Hz}, 3 \mathrm{H}, \mathrm{CH} 3), 1.54\left(\mathrm{~d}, J=7.8 \mathrm{~Hz}, 3 \mathrm{H}, \mathrm{CH}_{3}\right), 2.93(\mathrm{q}$, $\left.J=7.4 \mathrm{~Hz}, 2 \mathrm{H}, \mathrm{CH}_{2}\right), 3.34\left(\mathrm{~s}, 3 \mathrm{H}, \mathrm{N}-\mathrm{CH}_{3}\right), 4.24(\mathrm{q}, J=7.3 \mathrm{~Hz}, 1 \mathrm{H}$, $\mathrm{CH}), 7.42(\mathrm{t}, J=7.2 \mathrm{~Hz}, 1 \mathrm{H}, \mathrm{Ar}), 7.63(\mathrm{~d}, J=8.4 \mathrm{~Hz}, 1 \mathrm{H}, \mathrm{Ar}), 7.83(\mathrm{~d}$, $J=8.1 \mathrm{~Hz}, 1 \mathrm{H}, \mathrm{Ar}), 7.93$ (s, $1 \mathrm{H}, \mathrm{Ar}) .{ }^{13} \mathrm{C}$ NMR $\left(75.5 \mathrm{MHz}, \mathrm{DMSO}-d_{6}\right)$ : $11.4\left(\mathrm{CH}_{3}\right), 18.6\left(\mathrm{CH}_{2}\right), 20.7\left(\mathrm{CH}_{3}\right.$ heterocycle $), 29.5\left(\mathrm{~N}-\mathrm{CH}_{3}\right), 41.3(\mathrm{CH}$ heterocycle), $122.0(\mathrm{CH}, \mathrm{Ar}), 125.7$ (BrC, Ar), $128.9(\mathrm{CH}, \mathrm{Ar}), 130.7$ $(\mathrm{CH}, \mathrm{Ar}), 132.4(\mathrm{CH}, \mathrm{Ar}), 138.7(\mathrm{C}, \mathrm{Ar}), 163.2(\mathrm{C}=\mathrm{N}), 164.9(\mathrm{~S}-\mathrm{C}=\mathrm{N})$, $175.1(\mathrm{C}=\mathrm{O})$.

\section{2-((1-(3-bromophenyl)propylidene)hidrazono)-5-ethyl-3-} methylthiazolidin-4-one (2i)

The washing in ethanol afforded yellow powders, yield $=69 \%$. M.p. $\left({ }^{\circ} \mathrm{C}\right)$ : 187-189. Rf: 0.62 (Toluene/ethyl acetate 8:2). IR (KBr): 1722 $(\mathrm{C}=\mathrm{O}), 1605(\mathrm{C}=\mathrm{N}) \mathrm{cm}^{-1} .{ }^{1} \mathrm{H}$ NMR $\left(400 \mathrm{MHz}, \mathrm{DMSO}-d_{6}\right): 0.93(\mathrm{t}, J=$ $\left.7.2 \mathrm{~Hz}, 3 \mathrm{H}, \mathrm{CH}_{3}\right), 1.04\left(\mathrm{t}, J=7.6 \mathrm{~Hz}, 3 \mathrm{H}, \mathrm{CH}_{3}\right), 1.93\left(\mathrm{~m}, 2 \mathrm{H}, \mathrm{CH}_{2}-\mathrm{C} 5\right.$ heterocycle), $2.93\left(\mathrm{q}, J=3.2 \mathrm{~Hz}, 2 \mathrm{H}, \mathrm{CH}_{2}\right), 3.24\left(\mathrm{~s}, 3 \mathrm{H}, \mathrm{CH}_{3}\right), 4.24(\mathrm{q}, J=$ $3.0 \mathrm{~Hz}, 1 \mathrm{H}, \mathrm{CH}$ heterocycle), $7.44(\mathrm{t}, J=7.8 \mathrm{~Hz}, 1 \mathrm{H}, \mathrm{Ar}), 7.63(\mathrm{~d}, J=8.0$ $\mathrm{Hz}, 1 \mathrm{H}, \mathrm{Ar}), 7.84$ (d, J=7.6 Hz, 1H, Ar), 7.93 (s, 1H, Ar). ${ }^{13} \mathrm{C}$ NMR $(100$ MHz, DMSO- $\left.d_{6}\right): 10.3\left(\mathrm{CH}_{3}\right), 11.4\left(\mathrm{CH}_{3}\right), 20.8\left(\mathrm{CH}_{2}\right), 25.4\left(\mathrm{CH}_{2}\right), 29.4$ $\left(\mathrm{N}-\mathrm{CH}_{3}\right), 48.2(\mathrm{CH}$ heterocycle $), 122.0(\mathrm{CH}, \mathrm{Ar}), 125.7(\mathrm{BrC}, \mathrm{Ar}), 128.9$ $(\mathrm{CH}, \mathrm{Ar}), 130.7(\mathrm{CH}, \mathrm{Ar}), 132.5(\mathrm{CH}, \mathrm{Ar}), 138.7(\mathrm{C}, \mathrm{Ar}), 163.0(\mathrm{C}=\mathrm{N})$, $165.2(\mathrm{~S}-\mathrm{C}=\mathrm{N}), 174.2(\mathrm{C}=\mathrm{O})$.

2-((1-(3-bromophenyl)propylidene)hidrazono)-5-isopropyl3-methylthiazolidin-4-one (2j)

The washing in ethanol afforded yellow powders, yield $=92 \%$. M.p. $\left({ }^{\circ} \mathrm{C}\right)$ : 136-138. Rf: 0.59 (Toluene/ethyl acetate 8:2). IR (KBr): 1716 $(\mathrm{C}=\mathrm{O}), 1611(\mathrm{C}=\mathrm{N}) \mathrm{cm}^{-1} .{ }^{1} \mathrm{H}$ NMR $\left(400 \mathrm{MHz}, \mathrm{DMSO}-d_{6}\right): 1.02(\mathrm{t}, J=$ $\left.7.6 \mathrm{~Hz}, 3 \mathrm{H}, \mathrm{CH}_{3}\right), 1.52\left(\mathrm{~d}, J=7.2 \mathrm{~Hz}, 6 \mathrm{H}, \mathrm{CH}_{3}\right), 2.93(\mathrm{q}, J=7.2 \mathrm{~Hz}, 2 \mathrm{H}$, $\left.\mathrm{CH}_{2}\right), 3.34\left(\mathrm{~s}, 3 \mathrm{H}, \mathrm{N}-\mathrm{CH}_{3}\right), 4.24(\mathrm{q}, J=7.2 \mathrm{~Hz}, 1 \mathrm{H}, \mathrm{CH}$ heterocycle $)$, $7.44(\mathrm{t}, J=8.0 \mathrm{~Hz}, 1 \mathrm{H}, \mathrm{Ar}), 7.63(\mathrm{~d}, J=7.2 \mathrm{~Hz}, 1 \mathrm{H}, \mathrm{Ar}), 7.84(\mathrm{~d}, J=7.6$ $\mathrm{Hz}, 1 \mathrm{H}, \mathrm{Ar}), 7.94$ (s, $1 \mathrm{H}, \mathrm{Ar}) .{ }^{13} \mathrm{C}$ NMR $\left(100 \mathrm{MHz}, \mathrm{DMSO}-d_{6}\right): 10.1$ $\left(\mathrm{CH}_{3}\right), 11.2\left(\mathrm{CH}_{3}\right), 11.6\left(\mathrm{CH}_{3}\right), 13.8(\mathrm{CH}), 20.6\left(\mathrm{CH}_{2}\right), 29.1\left(\mathrm{~N}-\mathrm{CH}_{3}\right)$, $46.3(\mathrm{CH}$ heterocycle), $122.0(\mathrm{CH}, \mathrm{Ar}), 125.7(\mathrm{BrC}, \mathrm{Ar}), 128.9(\mathrm{CH}$, Ar), 130.7 (CH, Ar), 132.4 (CH, Ar), 138.7 (C, Ar), $163.2(\mathrm{C}=\mathrm{N}), 164.9$ $(\mathrm{S}-\mathrm{C}=\mathrm{N}), 175.1(\mathrm{C}=\mathrm{O})$.

\section{2-((1-(3-bromophenyl) propylidene)hidrazono $)-3,5,5$ -} trimethylthiazolidin-4-one (2k)

Recrystallization in toluene afforded yellowish crystals, yield = 31\%. M.p. $\left({ }^{\circ} \mathrm{C}\right)$ : $133-135$. Rf: 0.63 (Toluene/ethyl acetate 8:2). IR (KBr):
$1715(\mathrm{C}=\mathrm{O}), 1608(\mathrm{C}=\mathrm{N}) \mathrm{cm}^{-1} .{ }^{1} \mathrm{H}$ NMR $\left(300 \mathrm{MHz}, \mathrm{DMSO}-d_{6}\right): 0.93(\mathrm{t}$, $\left.J=5.25 \mathrm{~Hz}, 3 \mathrm{H}, \mathrm{CH}_{3}\right), 2.54\left(\mathrm{q}, J=7.7 \mathrm{~Hz}, 2 \mathrm{H}, \mathrm{CH}_{2}\right), 3.3(\mathrm{~s}, 6 \mathrm{H}, \mathrm{diMe})$, $5.64\left(\mathrm{~s}, 3 \mathrm{H}, \mathrm{N} 3-\mathrm{CH}_{3}\right), 7.54(\mathrm{t}, J=7.8 \mathrm{~Hz}, 1 \mathrm{H}, \mathrm{Ar}), 7.44(\mathrm{~d}, J=8.8 \mathrm{~Hz}$, $1 \mathrm{H}, \mathrm{Ar}), 7.63(\mathrm{~d}, J=8.1 \mathrm{~Hz}, 1 \mathrm{H}, \mathrm{Ar}), 7.93(\mathrm{~s}, 1 \mathrm{H}, \mathrm{Ar}) .{ }^{13} \mathrm{C} \mathrm{NMR}(75.5$ MHz, DMSO- $\left.d_{6}\right)$ : $10.4\left(\mathrm{CH}_{3}\right), 11.6\left(\mathrm{CH}_{2}\right), 21.6\left(\mathrm{CH}_{3}-\mathrm{N} 3\right), 28.3\left(\mathrm{CH}_{3}\right.$, heterocycle), $29.8\left(\mathrm{CH}_{3}\right.$, heterocycle), 51.2 (C, heterocycle), $122.7(\mathrm{CH}$, Ar), 124.9 (BrC, Ar), 125.4 (CH, Ar), $129.2(\mathrm{CH}, \mathrm{Ar}), 129.6(\mathrm{CH}, \mathrm{Ar})$, $132.6(\mathrm{C}, \mathrm{Ar}), 161.6(\mathrm{C}=\mathrm{N}), 166.2(\mathrm{~S}-\mathrm{C}=\mathrm{N}), 178.2(\mathrm{C}=\mathrm{O})$.

\section{2-((1-(3-bromophenyl)propylidene)hidrazono)-3-methyl-5- phenylthiazolidin-4-one (2l)}

The washing in ethanol afforded yellow powders, yield $=90 \%$. M.p. $\left({ }^{\circ} \mathrm{C}\right)$ : 128-130. Rf: 0.66 (Toluene/ethyl acetate 8:2). IR (KBr): 1709 $(\mathrm{C}=\mathrm{O}), 1619(\mathrm{C}=\mathrm{N}) \mathrm{cm}^{-1} .{ }^{1} \mathrm{H}$ NMR $\left(400 \mathrm{MHz}, \mathrm{DMSO}-d_{6}\right): 1.02(\mathrm{t}, J=$ $7.4 \mathrm{~Hz}, 3 \mathrm{H}, \mathrm{CH} 3), 2.22\left(\mathrm{~s}, 3 \mathrm{H}, \mathrm{CH}_{3}\right), 2.93\left(\mathrm{q}, J=7.5 \mathrm{~Hz}, 2 \mathrm{H}, \mathrm{CH}_{2}\right), 5.43$ (s, $1 \mathrm{H}, \mathrm{CH}$ heterocycle), $7.33(\mathrm{~m}, 6 \mathrm{H}, \mathrm{Ar}), 7.64(\mathrm{~d}, J=8.0 \mathrm{~Hz}, 1 \mathrm{H}, \mathrm{Ar}-$ $\mathrm{Br}), 7.84(\mathrm{~d}, J=8.0 \mathrm{~Hz}, 1 \mathrm{H}, \mathrm{Ar}-\mathrm{Br}), 7.93$ (s, $1 \mathrm{H}, \mathrm{Ar}-\mathrm{Br}) .{ }^{13} \mathrm{C}$ NMR $(100$ $\left.\mathrm{MHz}, \mathrm{DMSO}-d_{6}\right): 11.6\left(\mathrm{CH}_{3}\right), 13.8\left(\mathrm{CH}_{2}\right), 20.7\left(\mathrm{CH}_{3}-\mathrm{N} 3\right), 26.3(\mathrm{CH}$, heterocycle), $122.0(\mathrm{CH}, \mathrm{Ar}), 125.2$ (BrC, $\mathrm{Ar}), 125.6(\mathrm{CH}, \mathrm{Ar}), 128.1$ $(\mathrm{CH}, \mathrm{Ar}), 128.2(\mathrm{CH}, \mathrm{Ar}), 128.4(\mathrm{CH}, \mathrm{Ar}), 128.8(\mathrm{CH}, \mathrm{Ar}), 130.7(\mathrm{CH}$, Ar), 132.3 (C, Ar), 137.0 (C, Ar), $138.7(\mathrm{C}=\mathrm{N}), 163.6(\mathrm{~S}-\mathrm{C}=\mathrm{N}), 175.1$ $(\mathrm{C}=\mathrm{O})$.

\section{2-(( 1 - (3-bromophenyl) propilidene)hidrazono) - 3 -} phenylthiazolidin-4-one (2m)

The washing in ethanol afforded yellow powders, yield $=61 \%$. M.p. $\left({ }^{\circ} \mathrm{C}\right)$ : 168-170. Rf: 0.58 (Hexane/ethyl acetate 8:2). IR (KBr): 1720 $(\mathrm{C}=\mathrm{O}), 1602(\mathrm{C}=\mathrm{N}) \mathrm{cm}-1.1 \mathrm{H}$ NMR $(400 \mathrm{MHz}, \mathrm{DMSO}-\mathrm{d} 6): 0.84(\mathrm{t}, \mathrm{J}$ $=7.4 \mathrm{~Hz}, 3 \mathrm{H}, \mathrm{CH} 3), 2.63(\mathrm{q}, \mathrm{J}=8.8 \mathrm{~Hz}, 2 \mathrm{H}, \mathrm{CH} 2), 4.14(\mathrm{~s}, 2 \mathrm{H}, \mathrm{CH} 2$ heterocycle), $7.42(\mathrm{~m}, 6 \mathrm{H}, \mathrm{Ar}), 7.63(\mathrm{~d}, \mathrm{~J}=8.0 \mathrm{~Hz}, 1 \mathrm{H}, \mathrm{Ar}-\mathrm{Br}), 7.73$ (d, J = 8.0 Hz, 1H, Ar-Br), 7.93 (s, 1H, Ar-Br). 13C NMR (100 MHz, DMSO-d6): $11.3(\mathrm{CH} 3), 21.0(\mathrm{CH} 2), 32.3(\mathrm{CH} 2$ heterocycle), 122.0 (CH, Ar), 125.7 (BrC, Ar), $127.9(\mathrm{CH}, \mathrm{Ar}), 128.4(\mathrm{CH}, \mathrm{Ar}), 128.8(\mathrm{CH}$, Ar), 128.9 (CH, Ar), 130.7 (CH, Ar), 132.5 (CH, Ar), 135.0 (C, Ar), $138.6(\mathrm{~N} 3-\mathrm{C}, \mathrm{Ar}), 164.2(\mathrm{C}=\mathrm{N}), 165.3(\mathrm{~S}-\mathrm{C}=\mathrm{N}), 171.8(\mathrm{C}=\mathrm{O})$.

2-((1-(3-bromophenyl)propilidene)hidrazono)-5-methyl-3phenylthiazolidin-4-one (2n)

Recrystallization in toluene afforded yellowish crystals, yield = 68\%. M.p. $\left({ }^{\circ} \mathrm{C}\right): 141-143$. Rf: 0.69 (Hexane/ethyl acetate 8:2). IR ( $\left.\mathrm{KBr}\right)$ : $1724(\mathrm{C}=\mathrm{O}), 1605(\mathrm{C}=\mathrm{N}) \mathrm{cm}^{-1} .{ }^{1} \mathrm{H}$ NMR $\left(400 \mathrm{MHz}, \mathrm{DMSO}-d_{6}\right): 0.84$ $\left(\mathrm{t}, J=7.4 \mathrm{~Hz}, 3 \mathrm{H}, \mathrm{CH}_{3}\right), 1.63(\mathrm{~d}, J=7.2 \mathrm{~Hz}, 3 \mathrm{H}, \mathrm{CH} 3), 2.6(\mathrm{q}, J=7.6$ $\mathrm{Hz}, 2 \mathrm{H}, \mathrm{CH} 2), 4.44(\mathrm{q}, J=7.2 \mathrm{~Hz}, 1 \mathrm{H}, \mathrm{CH}$ heterocycle), $7.33(\mathrm{~m}, 5 \mathrm{H}$, Ar), 7.54 (t, $J=7.8 \mathrm{~Hz}, 1 \mathrm{H}, \mathrm{Ar}-\mathrm{Br}), 7.63$ (d, $J=7.0 \mathrm{~Hz}, 1 \mathrm{H}, \mathrm{Ar}-\mathrm{Br})$, $7.75(\mathrm{~d}, J=7.6 \mathrm{~Hz}, 1 \mathrm{H}, \mathrm{Ar}-\mathrm{Br}), 7.9$ (s, $1 \mathrm{H}, \mathrm{Ar}-\mathrm{Br}) .{ }^{13} \mathrm{C}$ NMR $(100$ $\mathrm{MHz}$, DMSO- $\left.d_{6}\right): 11.3\left(\mathrm{CH}_{3}\right), 18.7\left(\mathrm{CH}_{2}\right), 20.9\left(\mathrm{CH}_{3}\right), 41.3(\mathrm{CH}$ heterocycle), $122.0(\mathrm{CH}, \mathrm{Ar}), 125.7$ (BrC, Ar), 127.9 (CH, Ar), 128.5 (CH, Ar), $128.8(\mathrm{CH}, \mathrm{Ar}), 128.9(\mathrm{CH}, \mathrm{Ar}), 130.7(\mathrm{CH}, \mathrm{Ar}), 132.5(\mathrm{CH}$, Ar), 135.0 (C, Ar), 138.6 (N3-C, Ar), $162.9(\mathrm{C}=\mathrm{N}), 165.3(\mathrm{~S}-\mathrm{C}=\mathrm{N})$, $174.8(\mathrm{C}=\mathrm{O})$.

\section{2-((1-(3-bromophenyl)propylidene)hidrazono)-5-ethyl-3-} phenylthiazolidin-4-one (2o)

The washing in ethanol afforded yellow powders, yield $=90 \%$. M.p. $\left({ }^{\circ} \mathrm{C}\right): 121-123$. Rf: 0.68 (Toluene/ethyl acetate 8:2). IR (KBr): 1731 $(\mathrm{C}=\mathrm{O}), 1603(\mathrm{C}=\mathrm{N}) \mathrm{cm}^{-1} .{ }^{1} \mathrm{H}$ NMR $\left(400 \mathrm{MHz}, \mathrm{DMSO}-d_{6}\right): 0.83(\mathrm{t}, J=$ $\left.7.4 \mathrm{~Hz}, 3 \mathrm{H}, \mathrm{CH}_{3}\right), 1.03\left(\mathrm{t}, J=7.0 \mathrm{~Hz}, 3 \mathrm{H}, \mathrm{CH}_{3}\right), 2.04\left(\mathrm{~m}, 2 \mathrm{H}, \mathrm{CH}_{2}\right), 2.62$ $\left(\mathrm{q}, J=7.3 \mathrm{~Hz}, 2 \mathrm{H}, \mathrm{CH}_{2}\right), 4.43(\mathrm{t}, J=5.4 \mathrm{~Hz}, 1 \mathrm{H}, \mathrm{CH}$ heterocycle), 7.33 (m, 6H, Ar), $7.62(\mathrm{~d}, J=8.8 \mathrm{~Hz}, 1 \mathrm{H}, \mathrm{Ar}-\mathrm{Br}), 7.72(\mathrm{~d}, J=8.0 \mathrm{~Hz}, 1 \mathrm{H}, \mathrm{Ar}-$ 
Br), $7.91(\mathrm{~s}, 1 \mathrm{H}, \mathrm{Ar}-\mathrm{Br}) .{ }^{13} \mathrm{C}$ NMR $\left(100 \mathrm{MHz}, \mathrm{DMSO}-d_{6}\right): 10.1\left(\mathrm{CH}_{3}\right)$, $11.3\left(\mathrm{CH}_{3}\right), 21.0\left(\mathrm{CH}_{2}\right), 25.6\left(\mathrm{CH}_{2}\right), 48.2(\mathrm{CH}$ heterocycle $), 122.0(\mathrm{CH}$, Ar), 125.7 (BrC, Ar), 127.9 (CH, Ar), $128.5(\mathrm{CH}, \mathrm{Ar}), 128.8(\mathrm{CH}, \mathrm{Ar})$, 129.9 (CH, Ar), 130.7 (CH, Ar), 132.5 (CH, Ar), 134.9 (CH, Ar), 138.6 (N3-C, Ar), $162.7(\mathrm{C}=\mathrm{N}), 165.5(\mathrm{~S}-\mathrm{C}=\mathrm{N}), 173.9(\mathrm{C}=\mathrm{O})$.

2-((1-(3-bromophenyl)propylidene)hidrazono)-5-isopropyl3-phenylthiazolidin-4-one (2p)

Recrystallization in toluene afforded yellowish crystals, yield $=67 \%$. M.p. $\left({ }^{\circ} \mathrm{C}\right): 157-159$. Rf: 0.55 (Toluene/ethyl acetate 8:2). IR $(\mathrm{KBr}): 1725(\mathrm{C}=\mathrm{O}), 1566(\mathrm{C}=\mathrm{N}) \mathrm{cm}^{-1} .{ }^{1} \mathrm{H}$ NMR $\left(400 \mathrm{MHz}, \mathrm{DMSO}-d_{6}\right)$ : $0.82\left(\mathrm{~m}, 6 \mathrm{H}, \mathrm{CH}_{3}\right), 1.02\left(\mathrm{t}, J=7.6 \mathrm{~Hz}, 3 \mathrm{H}, \mathrm{CH}_{3}\right), 2.63(\mathrm{q}, J=5.3 \mathrm{~Hz}$, $\left.2 \mathrm{H}, \mathrm{CH}_{2}\right), 3.12(\mathrm{~m}, 1 \mathrm{H}, \mathrm{CH}$ isopropyl $), 4.52(\mathrm{~d}, J=3.8 \mathrm{~Hz}, 1 \mathrm{H}, \mathrm{CH}$ heterocycle), $7.42(\mathrm{~m}, 6 \mathrm{H}, \mathrm{Ar}), 7.63(\mathrm{~d}, J=7.6 \mathrm{~Hz}, 1 \mathrm{H}, \mathrm{Ar}-\mathrm{Br}), 7.84$ $(\mathrm{d}, J=7.9 \mathrm{~Hz}, 1 \mathrm{H}, \mathrm{Ar}-\mathrm{Br}), 7.93$ (s, $1 \mathrm{H}, \mathrm{Ar}-\mathrm{Br}) .{ }^{13} \mathrm{C}$ NMR $(100 \mathrm{MHz}$, DMSO- $\left.d_{6}\right): 10.9\left(\mathrm{CH}_{3}\right), 17.4\left(\mathrm{CH}_{3}\right), 20.8\left(\mathrm{CH}_{2}\right), 26.3(\mathrm{CH}, \mathrm{diMe}), 53.9$ ( $\mathrm{CH}$ heterocycle), $122.0(\mathrm{CH}, \mathrm{Ar}), 125.7$ (BrC, Ar), $127.9(\mathrm{CH}, \mathrm{Ar})$, 129.3 (CH, Ar), 129.5 (CH, Ar), 130.1 (CH, Ar), 130.9 (CH, Ar), 132.9 (CH, Ar), 135.5 (CH, Ar), 138.7 (C, Ar), $139.2(\mathrm{CH}, \mathrm{Ar}), 163.0(\mathrm{C}=\mathrm{N})$, $165.1(\mathrm{~S}-\mathrm{C}=\mathrm{N}), 172.7(\mathrm{C}=\mathrm{O})$.

2-(( 1 - (3-bromophenyl) propylidene)hidrazono ) -5,5dimethyl-3-phenylthiazolidin-4-one (2q)

Recrystallization in toluene afforded yellowish crystals, yield = 40\%. M.p. $\left({ }^{\circ} \mathrm{C}\right): 122-124$. Rf: 0.56 (Hexane/ethyl acetate 8:2). IR ( $\left.\mathrm{KBr}\right)$ : $1732(\mathrm{C}=\mathrm{O}), 1606(\mathrm{C}=\mathrm{N}) \mathrm{cm}^{-1} .{ }^{1} \mathrm{H}$ NMR $\left(400 \mathrm{MHz}, \mathrm{DMSO}-d_{6}\right): 0.85$ $\left(\mathrm{t}, J=7.4 \mathrm{~Hz}, 3 \mathrm{H}, \mathrm{CH}_{3}\right), 1.63\left(\mathrm{~s}, 6 \mathrm{H}, \mathrm{CH}_{3}\right), 2.63(\mathrm{q}, J=7.5 \mathrm{~Hz}, 2 \mathrm{H}$, $\left.\mathrm{CH}_{2}\right), 7.42(\mathrm{~m}, 6 \mathrm{H}, \mathrm{Ar}), 7.63(\mathrm{~d}, J=7.6 \mathrm{~Hz}, 1 \mathrm{H}, \mathrm{Ar}-\mathrm{Br}), 7.72(\mathrm{~d}, J=8.0$ $\mathrm{Hz}, 1 \mathrm{H}, \mathrm{Ar}-\mathrm{Br}), 7.93$ (s, $1 \mathrm{H}, \mathrm{Ar}-\mathrm{Br}) .{ }^{13} \mathrm{C}$ NMR (100 MHz, DMSO- $\left.d_{6}\right)$ : $11.2\left(\mathrm{CH}_{3}\right), 20.9\left(\mathrm{CH}_{2}\right), 27.8\left(\mathrm{CH}_{3}\right.$, heterocycle $), 50.8(\mathrm{C}$, heterocycle), 122.0 (CH, Ar), 125.7 (BrC, Ar), 128.0 (CH, Ar), 128.6 (CH, Ar), 128.8 $(\mathrm{CH}, \mathrm{Ar}), 130.7$ (CH, Ar), $132.5(\mathrm{CH}, \mathrm{Ar}), 135.0(\mathrm{CH}, \mathrm{Ar}), 138.5(\mathrm{C}$, $\operatorname{Ar}), 161.7(\mathrm{C}=\mathrm{N}), 165.3(\mathrm{~S}-\mathrm{C}=\mathrm{N}), 177.2(\mathrm{C}=\mathrm{O})$.

2-((1 - (3-bromophenyl) propylidene)hidrazono ) -3,5diphenylthiazolidin-4-one (2r)

The washing in ethanol afforded yellow powders, yield $=61 \%$. M.p. $\left({ }^{\circ} \mathrm{C}\right)$ : 183-185. Rf: 0.67 (Hexane/ethyl acetate 8:2). IR (KBr): 1728 $(\mathrm{C}=\mathrm{O}), 1602(\mathrm{C}=\mathrm{N}) \mathrm{cm}^{-1} .{ }^{1} \mathrm{H}$ NMR $\left(400 \mathrm{MHz}, \mathrm{DMSO}-d_{6}\right): 0.93(\mathrm{t}, J$ $\left.=7.2 \mathrm{~Hz}, 3 \mathrm{H}, \mathrm{CH}_{3}\right), 2.63\left(\mathrm{~d}, J=7.6 \mathrm{~Hz}, 2 \mathrm{H}, \mathrm{CH}_{2}\right), 5.62(\mathrm{~s}, 1 \mathrm{H}, \mathrm{CH}$ heterocycle), $7.42(\mathrm{~m}, 11 \mathrm{H}, \mathrm{ArH}), 7.72(\mathrm{~d}, J=7.6 \mathrm{~Hz}, 1 \mathrm{H}, \mathrm{Ar}-\mathrm{Br}), 7.93$ $(\mathrm{s}, 1 \mathrm{H}, \mathrm{Ar}-\mathrm{Br}) .{ }^{13} \mathrm{C}$ NMR $\left(100 \mathrm{MHz}, \mathrm{DMSO}-d_{6}\right): 11.3\left(\mathrm{CH}_{3}\right), 21.0\left(\mathrm{CH}_{2}\right)$, $50.2(\mathrm{CH}$, heterocycle), $122.0(\mathrm{CH}, \mathrm{Ar}), 125.7(\mathrm{BrC}, \mathrm{Ar}), 128.0(\mathrm{CH}$, Ar), $128.4(\mathrm{CH}, \mathrm{Ar}), 128.6(\mathrm{CH}, \mathrm{Ar}), 128.9(\mathrm{CH}, \mathrm{Ar}), 130.7(\mathrm{CH}, \mathrm{Ar})$, 132.6 (C, Ar), 135.0 (CH, Ar), 136.7 (CH, Ar), 138.5 (CH, Ar), 162.4 $(\mathrm{C}=\mathrm{N}), 165.8(\mathrm{~S}-\mathrm{C}=\mathrm{N}), 172.7(\mathrm{C}=\mathrm{O})$.

5-phenyl-2-[2-\{[4-(trifluoromethyl)phenyl $]$ methylidene $\}$ hydrazin-1-ylidene]-1,3-thiazolidin-4-one (3a)

White crystals; Yield 43\%; m.p. $\left({ }^{\circ} \mathrm{C}\right)$ 212-215; Rf: 0.61 (Toluene / ethyl acetate 7:3). IR $\left(\mathrm{KBr}, \mathrm{cm}^{-1}\right): 2943.43(\mathrm{NH}), 1723.06(\mathrm{C}=\mathrm{O})$, $1637.62(\mathrm{C}=\mathrm{N}) .{ }^{1} \mathrm{H}$ NMR $\left(400 \mathrm{MHz}, \mathrm{DMSO}-d_{6}\right), \delta$, ppm: $5.48(\mathrm{~s}, 1 \mathrm{H}$, $\mathrm{CH}$ thiazolidin-4-one), 7.35-7.39 (m, 5H, Ar), 7.81 (d, $J=8 \mathrm{~Hz}, 2 \mathrm{H}$, $\operatorname{Ar}), 7.96(\mathrm{~d}, J=7.2 \mathrm{~Hz}, 2 \mathrm{H}, \mathrm{Ar}), 8.55(\mathrm{~s}, 1 \mathrm{H}, \mathrm{HC}=\mathrm{N}), 12.10(\mathrm{~s}, 1 \mathrm{H}$, $\mathrm{NH}) .{ }^{13} \mathrm{C}$ NMR $\left(100 \mathrm{MHz}, \mathrm{DMSO}-d_{6}\right), \delta$, ppm: 51.9 (C, thiazolidin4-one), 122.7 ( $\left.\mathrm{CF}_{3}\right), 125.7$ (C, Ar), 126.2 (C, Ar), 126.2 (C, Ar), 128.7 (C, Ar), 128.9 (C, Ar), $129.4(\mathrm{C}, \mathrm{Ar}), 137.3(\mathrm{~N}=\mathrm{C}-\mathrm{S}), 138.6(\mathrm{C}=\mathrm{N})$, $155.3(\mathrm{C}=\mathrm{O})$. 5-methyl-2-[2-\{[4-(trifluoromethyl)phenyl]methylidene $\}$ hydrazin-1-ylidene]-1,3-thiazolidin-4-one (3b)

White crystals; Yield 45\%; m.p. $\left({ }^{\circ} \mathrm{C}\right)$ 239-241; Rf: 0.71 (Toluene / ethyl acetate 7:3). IR $\left(\mathrm{KBr}, \mathrm{cm}^{-1}\right): 2939.54(\mathrm{NH}), 1727.77(\mathrm{C}=\mathrm{O}), 1641.83$ $(\mathrm{C}=\mathrm{N}) .{ }^{1} \mathrm{H}$ NMR $\left(400 \mathrm{MHz}, \mathrm{DMSO}-d_{6}\right), \delta, \mathrm{ppm}: 1.51(\mathrm{~d}, J=7.2 \mathrm{~Hz}, 3 \mathrm{H}$, $\left.\mathrm{CH}_{3}\right), 4.23(\mathrm{~d}, J=7.2 \mathrm{~Hz}, 1 \mathrm{H}, \mathrm{CH}$ thiazolidin-4-one), $7.83(\mathrm{~d}, J=8.4 \mathrm{~Hz}$, $2 \mathrm{H}, \mathrm{Ar}), 7.96(\mathrm{~d}, J=8.4 \mathrm{~Hz}, 2 \mathrm{H}, \mathrm{Ar}), 8.51(\mathrm{~s}, 1 \mathrm{H}, \mathrm{HC}=\mathrm{N}), 12.05(\mathrm{~s}, 1 \mathrm{H}$, $\mathrm{NH}) .{ }^{13} \mathrm{C}$ NMR (100 MHz, DMSO- $\left.d_{6}\right), \delta$, ppm: $16.7\left(\mathrm{C}, \mathrm{CH}_{3}\right), 42.3(\mathrm{C}$, thiazolidin-4-one), 122.7 (CF3), 125.4 (C, Ar), 125.7 (C, Ar), 128.2 (C, Ar), $130.0(\mathrm{C}, \mathrm{Ar}), 130.3(\mathrm{C}=\mathrm{N}), 137.3(\mathrm{~N}=\mathrm{C}-\mathrm{S}), 154.9(\mathrm{C}=\mathrm{O})$.

2-[2-\{[4-(trifluoromethyl)phenyl]methylidene $\}$ hydrazin-1ylidene]-1,3-thiazolidin-4-one (3c)

White crystals; Yield 40\%; m.p. $\left({ }^{\circ} \mathrm{C}\right)$ 251-254; Rf: 0.45 (Toluene / ethyl acetate 7:3). IR ( $\left.\mathrm{KBr}, \mathrm{cm}^{-1}\right): 2941.46(\mathrm{NH}), 1710.55(\mathrm{C}=\mathrm{O})$, $1644.05(\mathrm{C}=\mathrm{N}) .{ }^{1} \mathrm{H}$ NMR $\left(400 \mathrm{MHz}, \mathrm{DMSO}-d_{6}\right), \delta$, ppm: $3.92(\mathrm{~s}, 2 \mathrm{H}$, thiazolidin-4-one), $7.83(\mathrm{~d}, J=8.4 \mathrm{~Hz}, 2 \mathrm{H}, \mathrm{Ar}), 7.96(\mathrm{~d}, J=8 \mathrm{~Hz}, 2 \mathrm{H}$, Ar), $8.50(\mathrm{~s}, 1 \mathrm{H}, \mathrm{HC}=\mathrm{N}), 12.08(\mathrm{~s}, 1 \mathrm{H}, \mathrm{NH}) .{ }^{13} \mathrm{C}$ NMR $(100 \mathrm{MHz}$, DMSO- $d_{6}$ ), $\delta$, ppm: 33.1 (C, thiazolidin-4-one), 122.7 (CF3), 125.4 (C, Ar), 125.7 (C, Ar), 128.2 (C, Ar), 130.0 (C, Ar), 130.3 (N=C-S), 138.1 $(\mathrm{C}=\mathrm{N}), 154.9(\mathrm{C}=\mathrm{O})$.

5-ethyl-2-[2-\{[4-(trifluoromethyl)phenyl] methylidene $\}$ hydrazin-1-ylidene]-1,3-thiazolidin-4-one (3d)

White crystals; Yield 65\%; m.p. $\left({ }^{\circ} \mathrm{C}\right)$ 235-237; Rf: 0.79 (Toluene / ethyl acetate 7:3). IR $\left(\mathrm{KBr}, \mathrm{cm}^{-1}\right): 2965.93(\mathrm{NH}), 1714.07(\mathrm{C}=\mathrm{O})$, $1641.98(\mathrm{C}=\mathrm{N}) .{ }^{1} \mathrm{H}$ NMR $\left(400 \mathrm{MHz}, \mathrm{DMSO}-d_{6}\right), \delta$, ppm: 0.96 (t, $J=7.2$ $\left.\mathrm{Hz}, 3 \mathrm{H}, \mathrm{CH}_{3}\right), 1.76-1.86\left(\mathrm{~m}, 1 \mathrm{H}, \mathrm{CH}_{2}\right), 1.94-2.02\left(\mathrm{~m}, 1 \mathrm{H}, \mathrm{CH}_{2}\right), 4.26(\mathrm{q}$, $J=8 \mathrm{~Hz}, 1 \mathrm{H}, \mathrm{CH}$ thiazolidin-4-one), $7.82(\mathrm{~d}, J=8 \mathrm{~Hz}, 2 \mathrm{H}, \mathrm{Ar}), 7.97(\mathrm{~d}$, $J=8 \mathrm{~Hz}, 2 \mathrm{H}, \mathrm{Ar}), 8.51(\mathrm{~s}, 1 \mathrm{H}, \mathrm{HC}=\mathrm{N}), 12.07(\mathrm{~s}, 1 \mathrm{H}, \mathrm{NH}) \cdot{ }^{13} \mathrm{C}$ NMR $(100$ MHz, DMSO- $\left.d_{6}\right), \delta$, ppm: $10.3\left(\mathrm{CH}_{3}\right), 25.4\left(\mathrm{CH}_{2}\right), 49.3(\mathrm{C}$, thiazolidin4-one), 122.7 (CF3), 125.4 (C, Ar), 125.7 (C, Ar), 128.2 (C, Ar), 130.0 (C, Ar), $130.3(\mathrm{~N}=\mathrm{C}-\mathrm{S}), 138.0(\mathrm{C}=\mathrm{N}), 155.0(\mathrm{C}=\mathrm{O})$.

5-(propan-2-yl) - 2 - [2- $\{[4-($ trifluoromethyl $)$ phenyl] methylidene\}hydrazin-1-ylide ne]-1,3-thiazolidin-4-one (3e)

White crystals; Yield 65\%; m.p. $\left({ }^{\circ} \mathrm{C}\right)$ 203-205; Rf: 0.70 (Toluene / ethyl acetate 7:3). IR $\left(\mathrm{KBr}, \mathrm{cm}^{-1}\right): 2965.62(\mathrm{NH}), 1722.03(\mathrm{C}=\mathrm{O})$, $1637.52(\mathrm{C}=\mathrm{N}) .{ }^{1} \mathrm{H}$ NMR $\left(400 \mathrm{MHz}, \mathrm{DMSO}-d_{6}\right), \delta$, ppm: 0.88 (d, $J=6.4$ $\left.\mathrm{Hz}, 3 \mathrm{H}, \mathrm{CH}_{3}\right), 1.00$ (d, J = 6.8 Hz, 3H, $\mathrm{CH}_{3}$ ), 2.47-2.50 (m, 1H, CH), 4.32 (d, $J=4 \mathrm{~Hz}, 1 \mathrm{H}$, thiazolidin-4-one), $7.82(\mathrm{~d}, J=7.6 \mathrm{~Hz}, 2 \mathrm{H}, \mathrm{Ar}), 7.80$ $(\mathrm{d}, J=8 \mathrm{~Hz}, 2 \mathrm{H}, \mathrm{Ar}), 8.50(\mathrm{~s}, 1 \mathrm{H}, \mathrm{HC}=\mathrm{N}), 12.08(\mathrm{~s}, 1 \mathrm{H}, \mathrm{NH}) .{ }^{13} \mathrm{C} \mathrm{NMR}$ (100 MHz, DMSO- $\left.d_{6}\right), \delta$, ppm: $16.4\left(\mathrm{CH}_{3}\right), 20.5\left(\mathrm{CH}_{3}\right), 29.9(\mathrm{CH}), 55.2$ (C, thiazolidin-4-one), 122.7 (CF3), 125.7 (C, Ar), 128.2 (C, Ar), 131.0 $(\mathrm{N}=\mathrm{C}-\mathrm{S}), 138.2(\mathrm{C}=\mathrm{N}), 154.7(\mathrm{C}=\mathrm{O})$.

3-methyl-5-phenyl-2-[2-\{[4-(trifluoromethyl)phenyl] methylidene\}hydrazin-1-ylidene]-1,3-thiazolidin-4-one (3f)

White crystals; Yield 40\%; m.p. $\left({ }^{\circ} \mathrm{C}\right)$ 245-248; Rf:0.62 (Toluene / ethyl acetate 7:3). IR $\left(\mathrm{KBr}, \mathrm{cm}^{-1}\right): 2943.43(\mathrm{NH}), 1723.06(\mathrm{C}=\mathrm{O})$, $1637.62(\mathrm{C}=\mathrm{N}) .{ }^{1} \mathrm{H}$ NMR (400 MHz, DMSO- $\left.d_{6}\right), \delta, \mathrm{ppm}: 3.33(\mathrm{~s}$, $\left.3 \mathrm{H}, \mathrm{CH}_{3}\right), 5.53(\mathrm{~s}, 1 \mathrm{H}$, thiazolidin-4-one) 7.35-7.40 (m, 5H, Ar), $7.82(\mathrm{~d}, J=7,6 \mathrm{~Hz}, 2 \mathrm{H}, \mathrm{Ar}), 7.97(\mathrm{~d}, J=7.6 \mathrm{~Hz}, 2 \mathrm{H}, \mathrm{Ar}), 8.56(\mathrm{~s}$, $1 \mathrm{H}, \mathrm{HC}=\mathrm{N}) .{ }^{13} \mathrm{C}$ NMR $\left(100 \mathrm{MHz}, \mathrm{DMSO}-d_{6}\right), \delta$, ppm: $30.9\left(\mathrm{C}, \mathrm{CH}_{3}\right)$, 51.2 (C, thiazolidin-4-one), 122.7 (C, Ar), 125.4 (C, Ar), 125.7 (CF3), 125.7 (C, Ar), 128.2 (C, Ar), 128.4 (C, Ar), 128.9 (C, Ar), 129.8 (C, Ar), 130.1 (C, Ar), 130.4 (C, Ar), 136.6 (C, Ar), 137.9 (C, Ar), 155.3 $(\mathrm{N}=\mathrm{C}-\mathrm{S}), 64.8(\mathrm{C}=\mathrm{N}), 174.7(\mathrm{C}=\mathrm{O})$. 


\section{3,5-dimethyl-2-[2-\{[4-(trifluoromethyl)phenyl]methylidene $\}$ hydrazin-1-ylidene]-1,3-thiazolidin-4-one (3g)}

White crystals; Yield $42 \%$; m.p. $\left({ }^{\circ} \mathrm{C}\right)$ 114-118; Rf: 0.75 (Toluene / ethyl acetate 7:3). IR $\left(\mathrm{KBr}, \mathrm{cm}^{-1}\right): 2939.54(\mathrm{NH}), 1727.77(\mathrm{C}=\mathrm{O})$, $1641.83(\mathrm{C}=\mathrm{N}) .{ }^{1} \mathrm{H}$ NMR $\left(300 \mathrm{MHz}, \mathrm{DMSO}-d_{6}\right), \delta, \mathrm{ppm}: 1.53(\mathrm{~d}, J=6.9$ $\left.\mathrm{Hz}, 3 \mathrm{H}, \mathrm{CH}_{3}\right), 3.19\left(\mathrm{~s}, 3 \mathrm{H}, \mathrm{CH}_{3}\right), 4.29(\mathrm{q}, J=7.1 \mathrm{~Hz}, 1 \mathrm{H}$, thiazolidin-4one), 7.83 (d, $J=7.8 \mathrm{~Hz}, 2 \mathrm{H}, \mathrm{Ar}), 7.98$ (d, $J=7.5 \mathrm{~Hz}, 2 \mathrm{H}, \mathrm{Ar}), 8.60$ (s, $1 \mathrm{H}, \mathrm{HC}=\mathrm{N}) .{ }^{13} \mathrm{C}$ NMR $\left(100 \mathrm{MHz}, \mathrm{DMSO}-d_{6}\right), \delta$, ppm: $18.6\left(\mathrm{C}, \mathrm{CH}_{3}\right)$, $29.5\left(\mathrm{C}, \mathrm{CH}_{3}\right), 41.4$ (C, thiazolidin-4-one), 125.8 (CF3), 125.7 (C, $\left.\mathrm{Ar}\right)$, 128.3 (C, Ar), 137.9 (C, Ar), $156.2(\mathrm{C}=\mathrm{N}), 165.1(\mathrm{~N}=\mathrm{C}-\mathrm{S}), 175.3(\mathrm{C}=\mathrm{O})$.

3-methyl-2-[2-\{[4-(trifluoromethyl)phenyl] methylidene $\}$ hydrazin-1-ylidene]-1,3-thiazolidin-4-one (3h)

White crystals; Yield 45\%; m.p. $\left({ }^{\circ} \mathrm{C}\right)$ 156-158; Rf: 0.70 (Toluene / ethyl acetate 7:3). IR $\left(\mathrm{KBr}, \mathrm{cm}^{-1}\right): 2941.46(\mathrm{NH}), 1710.55(\mathrm{C}=\mathrm{O}), 1644.05$ $(\mathrm{C}=\mathrm{N}) .{ }^{1} \mathrm{H}$ NMR $\left(300 \mathrm{MHz}, \mathrm{DMSO}-d_{6}\right), \delta$, ppm: $3.18\left(\mathrm{~s}, 3 \mathrm{H}, \mathrm{CH}_{3}\right), 3.99$ (s, 2H, thiazolidin-4-one), $7.84(\mathrm{~d}, J=8.1 \mathrm{~Hz}, 2 \mathrm{H}, \mathrm{Ar}), 7.99$ (d, $J=7,5$ $\mathrm{Hz}, 2 \mathrm{H}, \mathrm{Ar}), 8.61$ (s, $1 \mathrm{H}, \mathrm{HC}=\mathrm{N}) .{ }^{13} \mathrm{C}$ NMR $\left(100 \mathrm{MHz}, \mathrm{DMSO}-d_{6}\right), \delta$, ppm: $29.4\left(\mathrm{CH}_{3}\right), 32.2\left(\mathrm{CH}_{2}\right), 38.7$ (C, thiazolidin-4-one), $125.7\left(\mathrm{CF}_{3}\right)$, 125.8 (C, Ar), 128.3 (C, Ar), 138.0 (C, Ar), $156.2(\mathrm{~N}=\mathrm{C}-\mathrm{S}), 166.5(\mathrm{C}=\mathrm{N})$, $172.3(\mathrm{C}=\mathrm{O})$.

5-ethyl-3-methyl-2-[2-\{[4-(trifluoromethyl)phenyl] methylidene\}hydrazin-1-ylidene]-1,3-thiazolidin-4-one (3i)

White crystals; Yield 70\%; m.p. $\left({ }^{\circ} \mathrm{C}\right)$ 95.6- 98.9; Rf: 0.62 (Toluene / ethyl acetate 7:3). IR $\left(\mathrm{KBr}, \mathrm{cm}^{-1}\right): 2965.93(\mathrm{NH}), 1714.07(\mathrm{C}=\mathrm{O})$, $1641.98(\mathrm{C}=\mathrm{N}) .{ }^{1} \mathrm{H}$ NMR $\left(400 \mathrm{MHz}, \mathrm{DMSO}-d_{6}\right), \delta, \mathrm{ppm}: 0.83(\mathrm{t}, J$ $\left.=7.4 \mathrm{~Hz}, 1 \mathrm{H}, \mathrm{CH}_{3}\right), 0.96\left(\mathrm{t}, J=7.2 \mathrm{~Hz}, 1 \mathrm{H}, \mathrm{CH}_{3}\right), 1.03-1.09(\mathrm{~m}, 1 \mathrm{H}$, $\left.\mathrm{CH}_{3}\right), 1.44-1.62\left(\mathrm{~m}, 1 \mathrm{H}, \mathrm{CH}_{2}\right), 1.77-2.07\left(\mathrm{~m}, 1 \mathrm{H}, \mathrm{CH}_{2}\right), 3.19(\mathrm{~s}, 3 \mathrm{H}$, $\left.\mathrm{CH}_{3}\right), 4.31(\mathrm{q}, J=4,1 \mathrm{~Hz}, 1 \mathrm{H}$ thiazolidin-4-one), $7.84(\mathrm{~d}, J=8.4 \mathrm{~Hz}$, $2 \mathrm{H}, \mathrm{Ar}), 7.99(\mathrm{~d}, J=8 \mathrm{~Hz}, 2 \mathrm{H}, \mathrm{Ar}), 8.61(\mathrm{~s}, 1 \mathrm{H}, \mathrm{HC}=\mathrm{N}) .{ }^{13} \mathrm{C} \mathrm{NMR}(100$ $\left.\mathrm{MHz}, \mathrm{DMSO}-d_{6}\right), \delta$, ppm: $10.4\left(\mathrm{CH}_{3}\right), 25.6\left(\mathrm{CH}_{2}\right), 30.9\left(\mathrm{CH}_{3}\right), 49.4(\mathrm{C}$, thiazolidin-4-one), $125.4\left(\mathrm{CF}_{3}\right), 125.8$ (C, Ar), 127.7 (C, Ar), 128.3 (C, Ar), 137.9 (C, Ar), 139.8 (C, Ar), $156.4(\mathrm{~N}=\mathrm{C}-\mathrm{S}), 165.1(\mathrm{C}=\mathrm{N}), 178.0$ $(\mathrm{C}=\mathrm{O})$.

3-methyl-5-(propan-2-yl)-2-[2-\{[4-(trifluoromethyl)phenyl] methylidene\}hydrazin-1-ylidene]-1,3-thiazolidin-4-one (3j)

White crystals; Yield 50\%; m.p. $\left({ }^{\circ} \mathrm{C}\right)$ 97.8-101; Rf: 0.72 (Toluene / ethyl acetate 7:3). IR $\left(\mathrm{KBr}, \mathrm{cm}^{-1}\right): 2965.62(\mathrm{NH}), 1722.03(\mathrm{C}=\mathrm{O}), 1637.52$ $(\mathrm{C}=\mathrm{N}) .{ }^{1} \mathrm{H}$ NMR $\left(400 \mathrm{MHz}, \mathrm{DMSO}-d_{6}\right), \delta, \mathrm{ppm}: 0.91(\mathrm{~d}, J=6.4 \mathrm{~Hz}, 3 \mathrm{H}$, $\left.\mathrm{CH}_{3}\right), 1.07\left(\mathrm{~d}, J=6.8 \mathrm{~Hz}, 3 \mathrm{H}, \mathrm{CH}_{3}\right), 2.47-2.52(\mathrm{~m}, 1 \mathrm{H}, \mathrm{CH}), 4.47(\mathrm{~d}, J=$ $4.4 \mathrm{~Hz}, 1 \mathrm{H}$, thiazolidin-4-one), $7.89(\mathrm{~d}, J=8.4 \mathrm{~Hz}, 2 \mathrm{H}, \mathrm{Ar}), 8.06$ (d, $J=$ $8.4 \mathrm{~Hz}, 2 \mathrm{H}, \mathrm{Ar}), 8.68(\mathrm{~s}, 1 \mathrm{H}, \mathrm{HC}=\mathrm{N}) .{ }^{13} \mathrm{C}$ NMR (100 MHz, DMSO- $\left.d_{6}\right)$, $\delta$, ppm: $20.2\left(\mathrm{CH}_{3}\right), 29.3(\mathrm{CH}), 30.9\left(\mathrm{CH}_{3}\right), 54.0(\mathrm{C}$, thiazolidin-4-one), $125.5\left(\mathrm{CF}_{3}\right), 125.8$ (C, Ar), 128.3 (C, Ar), 130.5 (C, Ar), 1388.3 (C, Ar), $164.9(\mathrm{~N}=\mathrm{C}-\mathrm{S}), 173.8(\mathrm{C}=\mathrm{N}), 177.9(\mathrm{C}=\mathrm{O})$.

\section{Biological activity}

Cytotoxicity in mouse L-929 fibroblasts: The active compounds were tested in vitro for determination of cytotoxic over L-929 cells using the alamarBlue dye. Were used the same number of cells, time of the cell development and time of compound exposure used for the betagalactosidase assay. The cells were exposed to compounds (dissolved in DMSO) at increasing concentrations $(2.5 \mu \mathrm{g} / \mathrm{mL}$ until $160 \mu \mathrm{g} / \mathrm{mL})$, starting at an $\mathrm{IC}_{50}$ value of the T. cruzi. The compounds were tested in quadruplicate. After $96 \mathrm{~h}$ of exposure, alamarBlue was added and the absorbance at 570 and $600 \mathrm{~nm}$ was measured $6 \mathrm{~h}$ later. The cell viability was expressed as the percentage of difference in the reduction between treated and untreated cells $\mathrm{CC}_{50}$ values were calculated by linear interpolation and the selectivity index (SI) was determined based on the ratio between $\mathrm{CC}_{50}$ and $\mathrm{IC}_{50}$ values. Controls with uninfected cells, untreated infected cells, infected cells treated with BZD at $3.8 \mu \mathrm{M}$ (positive control) or DMSO 1\% were used.

Anti-T. cruzi activity (epimastigote): Epimastigotes (Dm28c strain) grown in LIT media were counted in a hemocytometer and then seeded at $10^{6}$ cells/well into a 96-well plate. Compounds were dissolved in DMSO and then diluted in LIT médium in a serial dilution (1.23, $3.70,11.11,33.33$ and $100 \mu \mathrm{g} / \mathrm{mL}$ ) and added to respective wells, in triplicate. The final DMSO concentration in the plate was $1 \%$. Plate was incubated for 5 days at $26^{\circ} \mathrm{C}$, aliquots of each well were collected, and the number of viable parasites were counted in a Neubauer chamber and compared to untreated parasite culture. Inhibitory concentration for $50 \%\left(\mathrm{IC}_{50}\right)$ was calculated using nonlinear regression on Prism 4.0 GraphPad software. BZD were used as the reference drug.

Anti-T. cruzi activity (trypomastigotes): Metacyclic trypomastigotes were collected from the supernatant of infected LLCMK2 cells and then seeded at $4 \times 10^{5}$ cells/well in RPMI-1640 medium. All compounds were dissolved in DMSO and then diluted in RPMI-1640 medium in a serial dilution $(1.23,3.70,11.11,33.33$ and $100 \mu \mathrm{g} / \mathrm{mL})$ and added to respective wells, in triplicate. The final DMSO concentration was $1 \%$. Plate was incubated for $24 \mathrm{~h}$ at $37{ }^{\circ} \mathrm{C}$ and $5 \%$ of $\mathrm{CO}_{2}$. Aliquots of each well were collected, and the number of viable parasites was counted in a Neubauer chamber. The percentage of inhibition was calculated in relation to untreated cultures. Cytotoxic concentration for $50 \%\left(\mathrm{CC}_{50}\right)$ was determined using nonlinear regression with Prism 4.0 GraphPad software. BZD were used as the reference drug

Anti-T. cruzi activity (amastigotes/trypomastigotes): T. cruzi (Tulahuen strain) expressing the Escherichia coli beta-galactosidase gene were grown on a monolayer of mouse L-929 fibroblasts. Cultures assayed for beta-galactosidase activity were grown in RPMI 1640 medium without phenol red plus $10 \%$ fetal bovine serum and glutamine. Ninety-six-well tissue culture microplates were seeded with L-929 fibroblasts at $4.0 \times 10^{3}$ per well in $80 \mu \mathrm{L}$ and incubated overnight at $37{ }^{\circ} \mathrm{C}, 5 \% \mathrm{CO}_{2}$. Beta-galactosidase-expressing trypomastigotes were then added at $4.0 \times 10^{4}$ per well in $20 \mu \mathrm{L}$. After $2 \mathrm{~h}$, the medium with trypomastigotes that have not penetrated in the cells was discarded and replaced by $200 \mu \mathrm{L}$ of fresh medium. After $48 \mathrm{~h}$, the medium was discarded again and replaced by $180 \mu \mathrm{L}$ of fresh medium and $20 \mu \mathrm{L}$ of test compounds dissolved in DMSO. Each compound was tested in quadruplicate. After 7 days culture development, chlorophenol red beta-D-galactopyranoside at $100 \mu \mathrm{M}$ and Nonidet P-40 at $0.1 \%$ were added to the plates and incubated overnight, at $37^{\circ} \mathrm{C}$. The absorbance was measured at $570 \mathrm{~nm}$ in an automated microplate reader. BZD at its $\mathrm{IC}_{50}(1 \mu \mathrm{g} / \mu \mathrm{L}=3.81 \mu \mathrm{M})$ was used as positive control. The results are expressed as a percentage of parasite growth inhibition. Two independent experiments were performed.

Statistical analysis: To determine the statistical significance of each group in the in vitro experiments, the one-way ANOVA test and the Bonferroni correction for multiple comparisons were used. A P value $<0.05$ was considered significant. The data are representative of at least two or three experiments run in triplicate.

\section{Acknowledgment}

This work was funded by Conselho Nacional de Desenvolvimento Científico e Tecnológico and Fundação de Amparo à Ciência e Tecnologia de Pernambuco (FACEPE). Ana Cristina Lima Leite is 
receiving a CNPq senior fellowship. Authors are thankful for the Departamento de Química Fundamental (DQF-UFPE) for recording the ${ }^{1} \mathrm{H}$ NMR, ${ }^{13} \mathrm{C}$ NMR, and IR spectra of compounds and Centro de Tecnologias Estratégicas do Nordeste (CETENE) for recording LCMS of all compounds. All authors declare no competing financial interest.

\section{References}

1. WHO, Chagas disease (American trypanosomiasis)

2. Pérez-Molina JA, Molina I (2018) Chagas disease. Lancet 391: 82-94. [Crossref]

3. Schmunis GA, Yadon ZE (2010) Chagas disease: a Latin American health problem becoming a world health problem. Acta Trop 115: 14-21. [Crossref]

4. Urbina JA (2009) New advances in the management of a long-neglected disease. Clin Infect Dis 49: 1685-1687. [Crossref]

5. Fabiana S, Jelicks LA, Kirchhoff LV, Shirani J, Nagajyothi F (2013) Cardiol Rev 20: 53-65.

6. Marin-Neto JA, Rassi A Jr, Avezum A Jr, Mattos AC, Rassi A, et al. (2009) The BENEFIT trial: testing the hypothesis that trypanocidal therapy is beneficial for patients with chronic Chagas heart disease. Mem Inst Oswaldo Cruz 104 Suppl 1: 319324. [Crossref]

7. Scarim CB, Jornada DH, Chelucci RC, de Almeida L, Dos Santos JL, et al. (2018) Current advances in drug discovery for Chagas disease. Eur J Med Chem 155: 824838. [Crossref]

8. Pinazo MJ, Muñoz J, Posada E, López-Chejade P, Gállego M, et al. (2010) Tolerance of benznidazole in treatment of Chagas' disease in adults. Antimicrob Agents Chemother 54: 4896-4899. [Crossref]

9. Leite ACL, Santos LMF, Barbosa FF (2006) Biomed. Pharmacother 60: 121-126.

10. de Oliveira FGB, de Oliveira MVC (2015) Bioorg. Med. Chem 23: 7478-7486.

11. Andres CJ, Bronson JJ, D'Andrea SV, Deshpande MS, Falk PJ, et al. (2000) 4-Thiazolidinones: novel inhibitors of the bacterial enzyme MurB. Bioorg Med Chem Lett 10: 715-717. [Crossref]

12. Küçükgüzel SG, Oruç EE, Rollas S, Sahin F, Ozbek A(2002) Synthesis, characterisation and biological activity of novel 4-thiazolidinones, 1,3,4-oxadiazoles and some related compounds. Eur J Med Chem 37: 197-206. [Crossref]

13. Bondock S, Khalifa W, Fadda AA (2007) Synthesis and antimicrobial evaluation of some new thiazole, thiazolidinone and thiazoline derivatives starting from 1-chloro3,4-dihydronaphthalene-2-carboxaldehyde. Eur J Med Chem 42: 948-954. [Crossref]

14. Verma A, Saraf SK (2008) 4-thiazolidinone--a biologically active scaffold. Eur J Med Chem 43: 897-905. [Crossref]
15. Aubé J (2012) Drug repurposing and the medicinal chemist. ACS Med Chem Lett 3: 442-444. [Crossref]

16. Kaiser M, Maes L, Tadoori LP, Spangenberg T, Ioset JR (2015) Repurposing of the open access malaria box for kinetoplastid diseases identifies novel active scaffolds against trypanosomatids. J Biomol Screen 20: 634-645. [Crossref]

17. Alvarez G, Varela J (2015) Antimicrob. Agents Chemother 59: 1398-1404.

18. Alvarez G, Varela J, Márquez P, Gabay M, Arias Rivas CE, et al. (2014) Optimization of antitrypanosomatid agents: identification of nonmutagenic drug candidates with in vivo activity. J Med Chem 57: 3984-3999. [Crossref]

19. GCS, UFD (2009) Antiinfect. Agents Med. Chem 8: 345-366.

20. Magalhaes DRM, de Oliveira ADT, de Moraes PATG (2014) Eur. J. Med. Chem 75 $467-478$

21. Du X, Guo C, Hansell E, Doyle PS, Caffrey CR, et al. (2002) Synthesis and structureactivity relationship study of potent trypanocidal thio semicarbazone inhibitors of the trypanosomal cysteine protease cruzain. J Med Chem 45: 2695-2707. [Crossref]

22. Álvarez-Hernández DA, Franyuti-Kelly GA, Díaz-López-Silva R (2018) Gen. México 81: $154-164$.

23. Hernandes MZ, Cavalcanti SM, Moreira DR, de Azevedo Junior WF, Leite AC (2010) Halogen atoms in the modern medicinal chemistry: hints for the drug design. Curr Drug Targets 11: 303-314. [Crossref]

24. de Moraes PATG, de Oliveira MB, Farias ES, de Oliveira MVC (2016) Eur. J. Med Chem 121: 387-398.

25. de Santana TI, Barbosa MO, Gomes PATM, da Cruz ACN, da Silva TG, et al. (2018) Synthesis, anticancer activity and mechanism of action of new thiazole derivatives. Eur J Med Chem 144: 874-886. [Crossref]

26. de Oliveira GBF (2017) Eur. J. Med. Chem 141: 346-361.

27. Jagodzinska M, Huguenot F, Candiani G, Zanda M (2009) Assessing the bioisosterism of the trifluoromethyl group with a protease probe. ChemMedChem 4: 49-51. [Crossref]

28. CALA (2004) 337-341.

29. Oprea TI, Gottfries J (1999) Toward minimalistic modeling of oral drug absorption. $J$ Mol Graph Model 17: 261-274, 329. [Crossref]

30. Veber DF, Johnson SR, Cheng HY, Smith BR, Ward KW, et al. (2002) Molecular properties that influence the oral bioavailability of drug candidates. $J$ Med Chem 45: 2615-2623. [Crossref]

31. Meanwell NA (2011) Improving drug candidates by design: a focus on physicochemical properties as a means of improving compound disposition and safety. Chem Res Toxicol 24: $1420-1456$. [Crossref]

Copyright: (C)2019 de Siqueira LRP. This is an open-access article distributed under the terms of the Creative Commons Attribution License, which permits unrestricted use, distribution, and reproduction in any medium, provided the original author and source are credited. 